\title{
DEL PROCESO DE BARCELONA A LA NUEVA AGENDA PARA EL MEDITERRÁNEO: EN BUSCA DE UN MODELO APROPIADO DE COOPERACIÓN
}

\author{
Antonio Blanc ${ }^{1}$ Eimys Ortiz ${ }^{2}$ \\ Universidad de Lleida
}

\begin{abstract}
Resumen:
El presente artículo analiza las relaciones euro-mediterráneas en los veinticinco años transcurridos desde el lanzamiento del Proceso de Barcelona en 1995 hasta su última revisión, la Nueva Agenda Mediterránea. La política euro-mediterránea se caracteriza por la búsqueda de un modelo apropiado de cooperación que ha pasado por distintas etapas desde la Conferencia de Barcelona sin lograr resultados tangibles. Las sucesivas iniciativas, la Política Europea de Vecindad y la Unión por el Mediterráneo, parten principalmente de acontecimientos internos que exigen actualizar su relación con la región, así como de parámetros de difícil alcance. Tras examinar las distintas políticas, el trabajo aborda si la Nueva Agenda continuará incurriendo en el declive o puede reactivar la visión común de un Mediterráneo estable, seguro y próspero.
\end{abstract}

Palabras Clave: Relaciones euro-mediterráneas; Proceso de Barcelona; Política Europea de Vecindad, Unión por el Mediterráneo, Nueva Agenda Mediterránea.

Title in English: From the Barcelona Process to the new agenda for the Mediterranean: In search of an appropriate model of cooperation

\begin{abstract}
:
This article analyses the Euro-Mediterranean relations in its twenty-fifth anniversary since the launch of the Barcelona Process in 1995 until its last review, the New Mediterranean Agenda. The EuroMediterranean policy is characterised by the search for an appropriate cooperation model and due to that fact, it has gone through different stages without achieving tangible results. The successive initiatives, the European Neighbourhood Policy and the Union for the Mediterranean, are mainly based on internal events that required updating their relationship with the region, including parameters that were difficult to reach as well. After examining the different policies, the article tries to explain whether the New Agendal will continue to make a contribution to its decline or can reactivate the common vision for a stable, secure and prosperous Mediterranean.
\end{abstract}

Key words: Euro-Mediterranean Relations; Barcelona Process; European Neighbourhood Policy; Union for the Mediterranean, New Agenda for the Mediterranean

Copyright (C) UNISCI, 2021.

Las opiniones expresadas en estos artículos son propias de sus autores, y no reflejan necesariamente la opinión de UNISCI. The views expressed in these articles are those of the authors, and do not necessarily reflect the views of UNISCI.

\footnotetext{
${ }^{1}$ Antonio Blanc Altemir es Catedrático de Derecho Internacional Público y RRII. Director de la Cátedra y del Centro de Excelencia Jean Monnet. Comisión Europea - Universitat de Lleida. E-mail: 〈antonio.blanc@udl.cat>

${ }^{2}$ Eimys Ortiz es Profesora Lector Serra Húnter de Derecho Internacional Público y RRII. Universitat de Lleida. E-mail: <eimys.ortiz@udl.cat> DOI: http://dx.doi.org/10.31439/UNISCI-127
} 


\section{Introducción}

El 28 de noviembre de 2020 y en plena segunda ola de la pandemia, se cumplieron veinticinco años de la Conferencia de Barcelona que en 1995 reunió en la Ciudad Condal a los quince ministros de Asuntos Exteriores de la entonces Unión Europea (UE) con sus doce homólogos de las orillas Sur y Este mediterráneas, incluyendo a israelíes y palestinos. A pesar de las enormes diferencias de todo tipo que existían entre ambas áreas, fueron capaces de aprobar un texto, la Declaración de Barcelona, que puede considerarse como el hito más importante del multilateralismo mediterráneo. La interdependencia creada con el paso del tiempo, así como la gran ampliación hacia el Centro y Este del continente exigió potenciar la cooperación a cambio de reformas democráticas, económicas y sociales de modo que se adoptó la Política Europea de Vecindad (PEV) en 2004. Por último, la dimensión regional se ha complementado con la creación de la Unión por el Mediterráneo (UpM) en 2008 que buscaba alejarse del contenido político y centrarse en proyectos concretos.

Transcurridos veinticinco años desde la mencionada Conferencia podemos constatar que no se han alcanzado los objetivos que se propusieron en su seno y que los diversos intentos por impulsar la cooperación euro-mediterránea, que se han puesto en marcha con posterioridad, no han satisfecho las expectativas generadas.

La persistencia de los conflictos presentes o latentes en el Mediterráneo -en particular el de Oriente Próximo- con todo su potencial de inestabilidad, han marcado durante los últimos años no solo las dinámicas internas de la región, sino también y de forma significativa la agenda de todo el proceso euro-mediterráneo. A pesar del voluntarismo tantas veces demostrado por la UE, y en particular de uno de sus estandartes más visibles durante los últimos años como ha sido el proceso de Barcelona, puede afirmarse al efecto que este ha estado prácticamente ausente en todos los conflictos surgidos en las riberas Sur y Este mediterráneas. En efecto ni la UE, ni el proceso euro-mediterráneo (PEM) han tenido un papel decisivo, lo que vale también para el conflicto de Libia y Siria, ni siquiera influencia alguna en los distintos conflictos que han azotado la orilla Sur del Mediterráneo en las últimas décadas, más allá del sempiterno conflicto de Oriente Próximo.

Con las turbulencias que aparecieron con la llamada primavera árabe y que rápidamente se expandieron como una mancha de aceite en la región mediterránea, se abrió una fase de contornos inciertos. La evolución de los acontecimientos tras las primeras elecciones democráticas en Túnez, la inestable transición en Egipto, la situación en Libia tras la intervención de la OTAN, así como la inquietante deriva que ha sacudido a Siria con todo su potencial de inestabilidad en el tablero de Oriente Medio, dibujan un escenario de alto riesgo para la seguridad en el Mediterráneo que requerirá mayores esfuerzos de cooperación en este ámbito, y en el que la hasta ahora poco visible UpM, debería revitalizarse, en la medida en que permite reforzar la dimensión regional y multilateral de las relaciones euro-mediterráneas.

Transcurridos ya diez años desde el estallido de la primavera árabe en las riberas Sur y Este mediterráneas que ha provocado profundas transformaciones en el panorama político y social de estos países, en particular en Siria por el conflicto armado que ya se ha cobrado más de medio millón de muertos y millones de refugiados, pero también en Libia, cuyo proceso de transición presenta todavía una gran inestabilidad, puede afirmarse que estas situaciones unidas al resto de factores de conflictividad, constituyen un desafío de grandes dimensiones para la estabilidad geopolítica del Mediterráneo. La Unión Europea, principal interesada en fomentar la estabilidad en la región mediterránea, debe sin lugar a dudas desempeñar un papel más activo a través de unas relaciones más integrales con sus vecinos del Sur, en el marco de una PEV reformada y de una UpM más visible en la región. 
Todo parece indicar que la estabilidad en la región mediterránea estará condicionada durante los próximos años al rumbo que adopten los diferentes procesos de transición en el vecindario Sur, pero también estará marcada por la evolución de otros escenarios conflictuales no menos preocupantes tanto en la propia región: la resolución del conflicto sirio, la situación en Libia o la deriva del conflicto árabe-israelí, como en regiones vecinas, en particular el Sahel, pero también el Golfo Pérsico. Por otra parte, conviene señalar que la intervención cada vez más directa de potencias regionales como Irán, Turquía o Arabia Saudí, sin olvidar Rusia, China y Estados Unidos, determina la acuciante necesidad de reorientar las relaciones euromediterráneas, en las que la UE, sin dejar de mirar al Este, debe prestar más atención a su flanco Sur.

Un análisis de la situación actual de los países donde se produjeron los estallidos sociales que desembocaron en la primavera árabe ${ }^{3}$, nos permite constatar que en el momento presente la inestabilidad en el área mediterránea es mucho mayor que la existente hace diez años cuando se iniciaron en Túnez las primeras revueltas. La irrupción del Daesh, con su potencial desestabilizador, ha constituido una amenaza no solo para la región sino también específicamente para Europa.

La crisis sanitaria, y con ella económica y social, que ha generado la pandemia hace más necesario que nunca el fortalecimiento de la cooperación euro-mediterránea ${ }^{4}$, a pesar del momento de incertidumbre presente en ambas orillas. Ello requiere sin duda altas dosis de voluntad política que parece menguar hoy en día ${ }^{5}$. Sin embargo, si se quiere definir una nueva agenda euro-mediterránea deberá contarse con todo el apoyo político en ambas riberas y que sea lo suficientemente audaz para integrar en su seno no solo las cuestiones económicas y financieras, ciertamente imprescindibles, sino también las sociales y culturales, que permita construir lo que el Alto Representante de las Naciones Unidas para la Alianza de Civilizaciones ha definido como un "demos mediterráneo"'.

De manera que en el presente artículo se llevará a cabo un balance crítico de las relaciones euro-mediterráneas a tenor de las trascendentales efemérides que se han cumplido a lo largo del año 2020: veinticinco años de la Conferencia de Barcelona, diez años desde la primavera árabe y cinco años desde la última revisión de la PEV. En particular, se valorará si la Nueva Agenda para el Mediterráneo, presentada en febrero de 2021, proporciona soluciones a las limitaciones conocidas y reconocidas de dicha política, y por lo tanto, si la Unión ha apostado por una visión ambiciosa e innovadora o si se ha mantenido en el déjà vu y en las declaraciones abstractas vacías de contenido real. Por este motivo, en primer lugar, se evaluará el Proceso de Barcelona incidiendo en las limitaciones en cada uno de los tres cestos que configuraron el documento. En segundo lugar, se dirimirá la PEV y sus consecutivos procesos de revisión en busca de una mayor adaptabilidad al contexto regional. En tercer lugar, se abordará la UpM que,

\footnotetext{
${ }^{3}$ Sobre su origen y desarrollo véase Blanc, Antonio (2012): La Unión Europea y el Mediterráneo. De los primeros acuerdos a la primavera árabe, Madrid, Tecnos, pp. 195 y ss.; Bassets, Lluís (2012): El año de la revolución: cómo los árabes están derrocando a sus tiranos, Madrid, Tecnos; González Del Miño, Paloma (ed.) (2014): Tres años de revoluciones árabes. Procesos de cambio, revoluciones internas y regionales, Madrid, Catarata.

${ }^{4}$ Cohen-Hadria, Emmanuel: "Covid-19: una prueba de resistencia para las relaciones euromediterráneas", EuroMeSCo (abril 2020), en https://www.euromesco.net/publication/covid-19-a-stress-test-for-euromediterranean-relations/

${ }^{5}$ Dado el hecho constatable de que durante los últimos años hemos asistido a una política euro-mediterránea menguante y en claro repliegue. En este sentido cfr. Escribano, Gonzalo: "Reducción de espacio de las políticas euro-mediterráneas", Real Instituto Elcano, ARI 68/2017 (12 septiembre 2017), en http://www.realinstitutoelcano.org/wps/portal/rielcano_es/contenido?WCM_GLOBAL_CONTEXT=/elcano/elca no_es/zonas_es/ari68-2017-escribano-reduccion-espacio-politicas-euro-mediterraneas

6 Moratinos, Miguel Ángel: "El Mediterráneo, 25 años después”, El País, 20 de noviembre de 2020, en https://elpais.com/opinion/2020-11-19/el-mediterraneo-25-anos-despues.html
} 
pese a su potencial inicial, ha quedado notablemente deslucida. Finalmente, se analizará la última iniciativa, la Nueva Agenda para el Mediterráneo, partiendo de su contenido y de sus características principales.

\section{La Conferencia de Barcelona: el punto de partida del Proceso Euro- mediterráneo}

La Asociación Euro- mediterránea (AEM), y con ella la nueva arquitectura mediterránea de la UE, arrancó en la Conferencia de Barcelona celebrada en noviembre de 1995 entre los quince Estados miembros y sus doce socios mediterráneos, en un intento de reorientar las relaciones entre ambas partes. La nueva concepción pasaba por el establecimiento de un "partenariado" global que reunía a los veintisiete socios mediterráneos en torno a un proyecto común basado en tres "cestos" o "pilares": el primero, de cooperación política y de seguridad; el segundo de cooperación económica y financiera; y el tercero, de cooperación social, cultural y humana.

Dos fueron como mínimo los factores que coadyuvaron al lanzamiento del Proceso de Barcelona: en primer lugar, un contexto internacional, pero también regional favorables; y, en segundo lugar, la voluntad política de los actores en presencia para establecer un nuevo marco de relaciones para el logro de un objetivo común.

En efecto, tanto el contexto global, con el fin de la Guerra Fría y la apuesta por el multilateralismo que se cristalizaba en un cierto relanzamiento de las Naciones Unidas (NNUU), como el europeo con una UE decidida a jugar un papel mucho más determinante en su vecindario Este y, en menor medida, en el Sur, constituyeron factores positivos para su éxito. De destacar igualmente por decisivo fue, no solo la reivindicación de los países mediterráneos de la ribera Sur de una mayor atención por parte de la UE, sino también el apoyo que a esta reclamación ofrecieron los países mediterráneos del Norte, en particular España, que asumía la presidencia europea en el segundo semestre de 1995, aunque también conviene subrayar el papel desempeñado por Francia, dada su vocación mediterránea, por Alemania, que también acabaría aceptando esta dimensión euro mediterránea arrastrando con ello a los países nórdicos que se habían mostrado distantes, y, finalmente, por Italia que sucedería a España en la presidencia de la UE, así como por las instituciones europeas.

La Declaración de Barcelona, adoptada tras los Acuerdos de Madrid y Oslo en un ambiente de quizás excesivo optimismo en relación con el conflicto árabe-israelí, subestimó en cierta medida la extraordinaria complejidad del proceso de paz en Oriente Próximo y su capacidad de condicionar de modo casi absoluto todo el PEM. Como se ha podido observar, las extraordinarias dificultades por las que ha pasado el proceso de paz en los últimos tiempos, han frenado de forma considerable el desarrollo pleno de la cooperación regional. Las diversas Conferencias Ministeriales han demostrado que, aunque formalmente podría argumentarse que el Proceso de Barcelona y el proceso de paz presentaban diferentes lógicas y dinámicas, en la práctica se encontraban indisolublemente unidos.

La creación de la AEM suscitó, por lo tanto, grandes esperanzas pues nació con una voluntad declarada de tolerancia y de aproximación entre los pueblos de ambas orillas. Existía además el convencimiento de que este espíritu conjunto de cooperación y solidaridad, inspirador de todo el proceso, debía desembocar, en buena lógica, en un clima de mayor comprensión mutua, al mismo tiempo que debía reducir las potenciales fuentes de conflicto. En este enfoque tuvo una especial significación el hecho de que el llamado Proceso de Barcelona se construyera desde el partenariado, lo que implicaba una relación entre iguales y no una imposición de unos, generalmente el Norte, sobre los otros, tradicionalmente el Sur.

El objetivo -sin duda ambicioso pues en último término implicaba el establecimiento progresivo de una zona común de paz, estabilidad y codesarrollo en el Mediterráneo- se concretó con la adopción de la Declaración de Barcelona y del correspondiente Programa de Trabajo para 
su puesta en marcha, a través de acciones específicas en los diferentes ámbitos de actuación. Pero, al mismo tiempo, la AEM suponía una voluntad decidida de la UE de reorientar su política mediterránea y de desempeñar un papel cada vez más activo en la región, tanto a nivel político, como económico y social, adoptando un enfoque más global a la vez que más estratégico, que superase las carencias de etapas anteriores.

En esta nueva fase, los objetivos a alcanzar pasaban por la creación de una zona común de paz y estabilidad; por el establecimiento de un área de prosperidad compartida, a través de la instauración de una zona de libre comercio (ZLC), así como del aumento sustancial de la ayuda financiera de la UE a sus socios; y, al mismo tiempo, por fomentar la comprensión entre las culturas y desarrollar los intercambios entre las sociedades civiles.

El Proceso de Barcelona partió, por lo tanto, con la firme determinación de avanzar en los tres frentes descritos, aunque conviene advertir que uno de sus ejes principales se basaba en la instauración de una zona de libre cambio (ZLC) entre la UE y sus socios mediterráneos, para lo cual la adopción y posterior aplicación de los Acuerdos Euro-mediterráneos constituía el principal instrumento. Y precisamente uno de los obstáculos más persistentes para el logro de este objetivo ha sido y continúa siendo la dificultad de los países socios mediterráneos (PSM) en superar la fase de transición hacia una economía más abierta, desarrollando al mismo tiempo la cooperación regional y subregional, lo que sin duda favorecería el proceso hacia el libre comercio.

Los Acuerdos de Asociación pretendían, de una forma más global e integral, una mayor aproximación entre la UE y sus socios mediterráneos, por lo que no se limitaban a la instauración progresiva del libre comercio, sino que cubrían otros ámbitos, como el apoyo a los procesos de transición y reestructuración económica, la diversificación de los sectores de cooperación incluyendo la sociedad civil, así como los compromisos asumidos en materia de democracia y derechos humanos. No obstante, dadas las grandes diferencias y el desigual grado de desarrollo de los países mediterráneos, los acuerdos intentaban adaptarse a la especificidad de cada socio y a sus necesidades particulares, de tal forma que en algunas ocasiones se concedía prioridad a la reestructuración económica y a la mejora de la competitividad y, en otras, a la reforma administrativa y de las estructuras económicas, pues todos ellos constituían factores interdependientes que no podían ser disociados del proceso global de aproximación entre las dos riberas mediterráneas, retomado con renovado ímpetu en la Conferencia de Barcelona.

\section{Las limitaciones del Proceso Euro-mediterráneo}

A pesar de que no puede ignorarse que la AEM ha sido el único foro regional de diálogo entre los PSM y la UE hasta el nacimiento de la UpM, aquella presenta una serie de limitaciones que han frenado un desarrollo más dinámico y progresivo. Entre ellas, algunas están íntimamente asociadas a las circunstancias del lanzamiento del PEM en la Conferencia de Barcelona, mientras otras, aunque presentan un carácter estructural, han evolucionado a lo largo de estos veinticinco años.

Sin lugar a dudas, uno de los límites intrínsecos del partenariado euro-mediterráneo ha venido determinado por su propio punto de partida. En efecto, la Declaración de Barcelona presentaba dosis nada desdeñables de voluntarismo a la vez que de ambición no siempre ajustada a la realidad de la región. Los Estados firmantes incorporaron en la Declaración posiciones y agendas divergentes e incluso en ocasiones contradictorias, en lugar de llevar a cabo una selección de prioridades adaptadas a las especificidades de cada país. Además, tras la adopción de la Declaración de Barcelona, la UE tuvo que prestar una atención preferente a la Agenda 2000 y a la ampliación al Este, así como a la puesta en marcha del euro o a la reforma institucional. 
Para llevar a cabo un análisis sistemático de las luces y sombras del PEM durante los años transcurridos desde su puesta en marcha, centraremos nuestra atención en los tres "pilares" o "cestos" en que se sustenta: la cooperación política y de seguridad; la cooperación económica y financiera; y la cooperación social, cultural y humana.

\subsection{La cooperación política y de seguridad}

\subsubsection{El diálogo político y la prevención de conflictos}

El balance de estos más de veinticinco años de andadura de la AEM presenta en este primer "cesto" un resultado desigual plagado de claroscuros. En primer lugar, y en relación con el objetivo de lograr una zona de paz y estabilidad, conviene señalar que el Mediterráneo es al menos tan conflictivo como en 1995, pues junto a los viejos conflictos (árabe-israelí, Sáhara occidental o Chipre), han aparecido otros nuevos como el de Siria o Libia que han tomado las relaciones euro-mediterráneas como rehén impidiendo que se abrieran nuevos espacios de cooperación ${ }^{7}$. Por otra parte, el PEM, cautivo del conflicto de Oriente Medio -realimentado de nuevo por la segunda intifada, la operación plomo fundido en Gaza y otros episodios posteriores, como la crisis de la "flotilla por la paz" o el lanzamiento de cohetes de Hamas y su consiguiente represalia por el ejército israelí a mediados de 2021- tampoco ha sido capaz de acometer la resolución de otros problemas presentes en la región, en particular los relativos a los recursos hídricos o energéticos, sectores en los que ya se reclamaba un incremento de la cooperación en la citada Declaración de Barcelona.

Por otra parte, el impacto de los conflictos de Afganistán, y en particular de Irak, potenció aún más las divergencias contribuyendo a crear una atmósfera enrarecida en la región que ha aportado más desencuentros que convergencias. Puede afirmarse al efecto que el PEM ha estado prácticamente ausente en todos los conflictos surgidos en las riberas Sur y Este mediterráneas en estos veinticinco años, dado que su pretensión era afrontar los nuevos problemas políticos, económicos y sociales en ambas orillas del Mediterráneo que constituían un desafío común ${ }^{8}$.

Podría objetarse frente a esta postura que el PEM no pretendía solucionar el conflicto de Oriente Próximo pues en el momento de realizarse la Conferencia de Barcelona, aquel parecía encontrarse en vías de solución en el marco entusiasta y casi eufórico que habían propiciado la Conferencia de Madrid y los Acuerdos de Oslo -ambiente que no debemos ignorar planeó sobre el desarrollo de la conferencia de Barcelona- ni tampoco otros conflictos presentes o latentes en la región. Sin embargo, no es menos cierto que a pesar de este "abstencionismo", el PEM intentó fomentar las condiciones propicias para establecer relaciones de buena vecindad, y de este modo apoyar los procesos dirigidos a lograr la estabilidad, la seguridad y la prosperidad, a través de la cooperación regional y subregional ${ }^{9}$.

Sin lugar a dudas esta estrategia se ha revelado como absolutamente equivocada, pues el PEM no ha conseguido crear un clima de entendimiento en los ámbitos de la seguridad, lo que por otra parte no es extraño pues resulta muy difícil dialogar sobre esta materia si

\footnotetext{
${ }^{7}$ Soler i Lecha, Eduard: "El Mediterráneo, veinticinco años después”, Anuario Internacional CIDOB, Barcelona Centre for International Affairs (junio 2020), pp. 176-184.

${ }^{8}$ Como afirmaba Ahmed Driss en 2009, ni la UE, ni el PEM han tenido un papel decisivo -lo que vale también para los conflictos de Libia y Siria- ni siquiera influencia alguna en los distintos conflictos que han azotado la orilla Sur del Mediterráneo: ni en la sangrienta guerra civil "larvada" que azotó a Argelia durante toda una década tras la victoria del FIS en 1992, que causó más de 150.000 muertos; ni en el conflicto del Sáhara Occidental, ni tampoco en un conflicto menor como el de la Isla de Perejil entre España y Marruecos, ni por supuesto en el sempiterno conflicto de Oriente Próximo, pues los mecanismos del partenariado euro-mediterráneo han estado totalmente ausentes. Cfr. Driss, Ahmed.: "El diálogo político y de seguridad euro-mediterráneo", Med 2009 Anuario del Mediterráneo, Barcelona, IEMed, pp. 94 y 95.

${ }^{9}$ Tal como se indica en el cesto de cooperación política y de seguridad de la Declaración de Barcelona.
} 
previamente no se han solucionado los conflictos existentes ${ }^{10}$, aunque en un principio ello no constituyó un hándicap para intercambiar puntos de vista en estos temas, a pesar de que no se llegara a realizaciones concretas ${ }^{11}$.

El fomento del diálogo político se incluyó en la Declaración de Barcelona como una de las cuestiones centrales de este primer cesto, partiendo de la convicción de que el establecimiento de vías estables y regulares de comunicación entre la UE y los PSM constituiría una garantía para la prevención de conflictos, así como para favorecer la confianza mutua, no solo entre ambas riberas mediterráneas sino también entre los propios PSM. Sin embargo, durante estos veinticinco años de andadura, el diálogo desarrollado no puede calificarse de relevante sino más bien de limitado y formal ${ }^{12}$.

El tratamiento de las cuestiones de seguridad en el PEM durante los años transcurridos desde la conferencia de Barcelona, ha ido evolucionando en paralelo a las circunstancias que se han desarrollado en la región mediterránea ${ }^{13}$. A las tres etapas que, de acuerdo con Aliboni ${ }^{14}$, pueden distinguirse en estos años de andadura de la AEM, podríamos añadir, en nuestra opinión, una cuarta que se abre con los acontecimientos de la primavera árabe y su repercusión en la estabilidad y seguridad de la región, sin ignorar, aunque para ello todavía no existe la perspectiva temporal suficiente, los efectos de la pandemia en la región mediterránea.

En efecto, a la primera etapa coincidente con la fase de euforia que caracterizó la Conferencia de Barcelona, corresponderían las propuestas relativas a los aspectos más centrales de la seguridad en sentido estricto, tales como el desarme, en particular de armas de destrucción masiva. En este sentido la UE intentó, en la medida de sus posibilidades, cooperar con sus socios mediterráneos para la consecución de los objetivos incorporados en la Declaración de Barcelona en este ámbito, en particular para lograr una zona libre de todo tipo de armas de destrucción masiva en el Mediterráneo y para que todos los países mediterráneos cumplieran con sus obligaciones internacionales en esta materia.

Sin embargo, las dificultades para la aprobación definitiva de la Carta Euromediterránea para la Paz y la Estabilidad, que constituye uno de los objetivos más antiguos de la AEM y que ha sido bloqueado repetidamente por el conflicto de Oriente Próximo, desembocó en un abandono del proyecto ${ }^{15}$, lo que visualiza un cierto fracaso pues el proceso de Barcelona

\footnotetext{
${ }^{10}$ Chourou, Béchir: "The (ir)relevance of security issues in Euro-Mediterranean Relations", en Tanner, Fred (ed.) (2001): The European Union as a security actor in the Mediterranean: EDSP, soft power and peacemaking in Euro-Mediterranean relations, Zürich, Forschungsstelle für sicherheitspolitik und konfliktanalyse dert ETH, p. 64.

${ }^{11}$ Sobre la dimensión de la seguridad en la región mediterránea a los dos años de la Declaración de Barcelona, puede verse el núm. 37 (1997) de la Revista CIDOB d'Afers Internacionals, dedicado a "Estabilidad y conflictos en el Mediterráneo", en particular Marquina, Antonio: "Seguridad y estabilidad política en el Mediterráneo", pp. 39-52 y Biad, Abdelwahad: "A strategy for conflict prevention and management in the Mediterranean", pp. 5363.

${ }^{12}$ Le Morzellec, Joëlle: "Le partenariat euro-méditerranéen: la consolidation d'une zone de paix et de stabilité", en Osman, Filali; Philip, Christian (dirs.) (2003): Le partenariat euro-méditerranéen. Le processus de Barcelone: nouvelles perspectives, Bruxelles, Bruylant, pp. 65-83.

${ }^{13}$ En efecto, el PEM ha debido afrontar las dificultades derivadas de una situación muy compleja en el Mediterráneo en el que las cuestiones de seguridad tradicional o de hard security (conflictos interesatatales, proliferación de armas...) se han entrelazado con las cuestiones de seguridad en sentido amplio o de soft security (lucha contra el terrorismo, criminalidad organizada...). Bremberg-Heijl, Niklas: "Between a rock and a hard place: Euro-Mediterranean security revisited", Mediterranean Politics, vol. 12, no 1 (2007), pp. 11 y ss.

${ }^{14}$ Aliboni, Roberto: "10 ans de dialogue politique et de sécurité au sein du processus du Barcelone: une tentative d'évaluation", Géoéconomie, no 35 (otoño 2005), pp. 101-121.

${ }^{15}$ Para un análisis de las vicisitudes seguidas en los primeros años por la Carta Euro-mediterránea para la Paz y la Estabilidad, véase Marquina, Antonio: "La asociación de seguridad de la Conferencia Euro-Mediterránea diez años después: la anábasis", UNISCI Discussion Papers, n 9 (2005), pp. 73 y ss.; Bacot-Décriaud, Michèle; Plantin,
} 
no ha sido capaz de constituirse en el lugar central en el que se definan las bases de acción común en este ámbito, debiendo recurrir a los acervos de otros foros e instancias.

A pesar de su carácter formalmente no vinculante, la adopción de la Carta Euromediterránea para la Paz y la Estabilidad, hubiera contribuido a marcar las grandes líneas de actuación en materia de seguridad, así como a definir un concepto de seguridad compartida, todavía inexistente en la región mediterránea. El abandono o "aparcamiento" del proyecto denota las insalvables carencias y deficiencias que presenta la AEM en este ámbito, así como la falta de convergencia entre la UE y los PSM, derivadas tanto de la centralidad que para estos representa el conflicto de Oriente Medio, como de la percepción de una UE débil en el campo de la seguridad por parte de sus socios ${ }^{16}$.

La segunda etapa se caracterizó por una cierta ralentización del proceso ante el empeoramiento del conflicto israelí-palestino, que, una vez más, condicionó cualquier avance. Sin embargo y de forma paralela, se pusieron en marcha determinadas iniciativas de fomento del partenariado, como la red EuroMeSCo o los seminarios para diplomáticos en Malta, que intentaron superar la sensación de un cierto estancamiento que parecía instalarse en este ámbito.

La tercera fase incorporó, coincidiendo con el relanzamiento de otras iniciativas regionales o subregionales, como el Diálogo Mediterráneo de la OTAN ${ }^{17}$ o la Iniciativa $5+5^{18}$, la cooperación en el marco de la entonces Política Europea de Seguridad y Defensa (PESD), aunque de una forma incipiente y con el objetivo de potenciarla tanto en el ámbito regional, como subregional y bilateral, y desarrollar de esta forma líneas de actuación destinadas a la prevención de conflictos y la gestión de crisis ${ }^{19}$.

Con las turbulencias que provocaron las primaveras árabes en la región mediterránea, cuya onda sísmica todavía no ha terminado, se abrió una cuarta fase de contornos inciertos. La evolución de los acontecimientos tras las primeras elecciones democráticas en Túnez, la situación en Libia y el bajo perfil de la UE en el conflicto, así como la inquietante deriva de la situación en Siria al que se añadió la amenaza del programa nuclear iraní, dibujan un escenario de alto riesgo para la seguridad en el Mediterráneo que requerirá mejores diseños y mayores esfuerzos de cooperación en este ámbito.

\subsubsection{La promoción de los derechos humanos y de los valores democráticos}

Por otra parte, y en lo relativo a otras materias incluidas en este primer cesto como la defensa de los derechos humanos y la promoción de los valores democráticos, conviene señalar que los

\footnotetext{
Marie Claude: "Un joker. La charte euro-méditerranéenne pour la paix et la stabilité", en Osman et al.: Le partenariat euro-méditerranéen..., op. cit., pp. 85-99.

${ }^{16}$ Las dificultades en la adopción de la Carta confirman la dificultad de crear una convergencia en torno a una noción de seguridad común fuertemente anclada en su dimensión humana, en la que el respeto a los derechos humanos constituiría la pre-condición y la post-condición a la paz y la seguridad internacional. Di Stasi, Angela: "La sécurité régionale dans l'espace euroméditerranéen. Processus de Barcelone et Union pour la Méditerranée", Revue juridique de l'Ouest, $\mathrm{n}^{\circ} 2$ (2010), p. 197.

${ }^{17}$ Yáñiz, Federico: "El Diálogo Mediterráneo de la OTAN y las crisis árabes”, Real Instituto Elcano, ARI, nº 108/2011 (junio 2011), en

http://www.realinstitutoelcano.org/wps/portal/rielcano_es/contenido?WCM_GLOBAL_CONTEXT=/elcano/elca no_es/zonas_es/defensa+y+seguridad/ari108-2011. Un análisis más reciente puede verse en Marquina, Antonio: "El Diálogo Mediterráneo de la OTAN, 2. Nuevas ilusiones y un espejismo: la democratización y la transformación del espacio mediterráneo", Comentario UNISCI, n 134 (2018).

${ }^{18}$ Echeverría, Carlos: "Lecciones aprendidas por el Grupo 5+5 en sus trabajos en materia de seguridad y defensa y perspectivas de futuro", en Soler i Lecha, Eduard; Hilali, Fadela (eds.) (2009): VII Seminario Internacional sobre Seguridad y Defensa en el Mediterráneo. Conflictos regionales y estrategias de seguridad, Barcelona, CIDOB, pp. 55-61.

${ }^{19}$ En un contexto en el que la participación de los socios mediterráneos en las Misiones PESD abrió nuevas perspectivas de cooperación en materia de seguridad que deberían potenciarse en la región mediterránea.
} 
avances tampoco han sido significativos. La causa de este balance más que discreto se debe no solo, aunque principalmente, a las condiciones políticas y sociales por las que atraviesan los PSM, sino también a la actitud pasiva y condescendiente de la UE que ha preferido no utilizar los instrumentos que tiene en su poder, como son su propio potencial económico y la cláusula democrática incorporada en los diferentes Acuerdos de Asociación, lo que parece evidenciar una falta de voluntad política en avanzar decididamente por este camino, sin ignorar los condicionamientos también políticos que sin duda existen en este ámbito. Para paliar esta situación se institucionalizó desde finales de 2003 un diálogo informal en materia de Derechos Humanos en el marco de la PEV y se concluyeron Planes de Acción que incluyen compromisos concretos adoptados de común acuerdo para la promoción de los derechos humanos, en particular con aquellos países mediterráneos que ya habían ratificado los Acuerdos de Asociación.

Partiendo de la convicción de que las medidas de reforma política en favor de los derechos humanos y de la democracia, constituyen un paso previo a la consecución de una seguridad y estabilidad duraderas, la Comisión Europea adoptó en mayo de 2003 una comunicación consagrada a la cooperación en materia de derechos humanos y democratización ${ }^{20}$, apelando a que estas materias debían ser objeto de una atención prioritaria por parte de la AEM. A tal efecto, los socios euro-mediterráneos deberían examinar los objetivos concretos a alcanzar en este ámbito, en particular la implantación de políticas que favorezcan la igualdad entre hombres y mujeres, la promoción de los derechos sociales, de la sociedad civil y del desarrollo.

A pesar de que la UE ha adoptado políticas e instrumentos para el fomento de la democracia y los derechos humanos a escala global ${ }^{21}$, que se destinan igualmente a la región mediterránea, como el Instrumento Europeo para la Democracia y los Derechos Humanos, que expiró el 31 de diciembre de 2013 siendo sustituido por el Instrumento Financiero para la Democracia y los Derechos Humanos a escala mundial ${ }^{22}$, es evidente que su efectividad ha sido muy limitada en la ribera Sur mediterránea.

Por otra parte, puede afirmarse que el principio de condicionalidad no ha funcionado, ni el incorporado a los diversos Acuerdos de Asociación, ni tampoco el que de una forma más proactiva introdujo la PEV al subrayar la acción más en los estímulos que en las sanciones con la promesa de más apertura en los mercados comunitarios y más apoyo a las reformas. A pesar de algunos avances puntuales auspiciados por los distintos instrumentos adoptados tanto por el PEM como por la PEV, es evidente que la convicción de la UE de que el libre comercio y las ayudas financieras conducirían a los socios mediterráneos por la senda de la democratización y las reformas de los sistemas políticos y económicos ha fracasado ${ }^{23}$ como pusieron de manifiesto las turbulencias acaecidas en el mundo árabe.

\footnotetext{
${ }^{20}$ Donner une nouvelle impulsion aux actions menées par l'UE dans le domaine des droits de l'homme et de la démocratisation, en coopération avec les partenaires méditerranéens, COM (2003)294.

${ }^{21}$ Alberdi, Jokin: "Instrumentos y políticas de la cooperación europea al desarrollo para el fomento de la democracia y los derechos humanos en terceros países", en Innerarity, Daniel; Aymerich, Ignacio (coords.) (2016): Derechos humanos y Políticas públicas europeas, Barcelona, Paidós, pp. 69-88.

${ }^{22}$ Creado por el Reglamento (UE) no 235/2014 del Parlamento Europeo y del Consejo, de 11 de marzo de 2014, por el que se establece un instrumento financiero para la democracia y los derechos humanos a escala mundial (2014-2020).

${ }^{23}$ Véase en este sentido Gillespie, Richard; Youngs, Richard (eds.) (2002): The European Union and Democracy Promotion. The Case of North Africa, Londres, Frank Cass Publishers; Schmid, Dorothée: "Le partenariat, une méthode européenne de démocratisation en Méditerranée?”, Politique étrangère, no 3 (2005), pp. 545-557.
} 


\subsubsection{Los flujos migratorios y la lucha contra el terrorismo y la delincuencia organizada}

En cuanto a otras cuestiones relativas a la lucha contra la inmigración irregular, el terrorismo y el crimen organizado, conviene advertir que aunque figuraban formalmente incorporadas en el tercer cesto de la Declaración de Barcelona, el hecho de que se trate de materias asociadas a la cooperación en materia política y de seguridad, determinó que se incluyeran a efectos prácticos en el primer cesto, en el que, por otra parte aparecía igualmente una referencia a las mismas, en particular a la lucha contra el terrorismo y la delincuencia organizada, pero no así a la inmigración irregular que aparecía exclusivamente en el tercer cesto. El Plan de Acción aprobado en la Conferencia de Valencia hacía una mención expresa a la puesta en marcha de un programa regional de cooperación en materia de justicia, lucha contra el crimen organizado y contra el terrorismo, así como sobre la gestión de los flujos migratorios y la integración de los inmigrantes en territorio comunitario.

La adopción del documento marco regional en Valencia, la posterior aprobación del programa "Justicia, Libertad y Seguridad", así como la inclusión de un "cuarto cesto" en el Programa de Trabajo de la Conferencia Extraordinaria de Barcelona de $2005^{24}$, dieron mayor visibilidad a la cooperación entre los socios mediterráneos de ambas orillas en estas materias, aunque sin duda quedaba mucho por hacer ${ }^{25}$. La Comisión ha venido considerando al respecto, que los Acuerdos de Asociación y los Planes de Acción de la PEV deberían jugar un papel determinante, en particular a través del diálogo institucional que se ha venido desarrollando en el seno del Sub-Comité "Justicia y Seguridad" y del Grupo de Trabajo "Migraciones y Asuntos Sociales". Se trata de una cuestión de especial sensibilidad particularmente para la UE que pretende, no obstante, hacerla extensiva a los PSM con mensajes más cercanos a los intereses de estos como la optimización de los flujos migratorios en interés de toda la región, la integración social de los inmigrantes o la intensificación de la cooperación para evitar las tragedias humanas tan frecuentes en este ámbito.

Desde la entrada en vigor del Tratado de Ámsterdam en 1999, los Estados miembros de la UE se dedicaron a negociar y suscribir acuerdos de readmisión con los países de origen o tránsito de migrantes, en muchos casos con los países de la ribera sur. El Consejo Europeo de Sevilla de 2002, validó esta política de concesión recíproca, imponiendo cláusulas de readmisión en todos los acuerdos de cooperación, estableciéndose de esta forma una condicionalidad de la ayuda al desarrollo a la gestión de los flujos migratorios y a la lucha contra la inmigración irregular. Más allá de las pretensiones de movilidad justificadas por el Sur en la seguridad humana, y de las ayudas económicas condicionadas a tales compromisos, el interés de los Estados europeos se centró en reenviar lo más rápidamente posible a las personas en situación irregular, así como en superar todo obstáculo jurídico o administrativo que se oponga a los retornos. Los acuerdos de readmisión se han inscrito por lo tanto en una lógica global securitaria, cuyo fundamento es proteger a cualquier precio las fronteras europeas, impidiendo a los irregulares su entrada y expulsando a los que, a pesar de todas las trabas, han logrado entrar en su territorio.

En definitiva, el reto sería ir más allá de un tratamiento exclusivamente centrado desde la óptica de la seguridad, en el que a través de los Acuerdos de Asociación y de los Planes de Acción de la PEV, pudiera concebirse una gestión conjunta de la circulación de personas y la integración de los inmigrantes que pusiera el acento en la lucha contra la discriminación y la exclusión social, objetivos que requieren un consenso que todavía parece lejos de alcanzarse, a

\footnotetext{
${ }^{24}$ Dedicado a "Migración, Integración social, Justicia y Seguridad".

${ }^{25}$ Sobre esta cuestión, cfr. Blázquez, Irene: "La dimensión mediterránea del espacio de libertad, seguridad y justicia. Del proceso de Barcelona a la Unión Europea por el Mediterráneo”, Revista Electrónica de Estudios Internacionales, $\mathrm{n}^{\circ} 19$ (junio 2010), pp. 1-26.
} 
pesar de los avances puntuales que pudieron apreciarse desde la Cumbre Euro-mediterránea de $2005^{26}$.

Más recientemente, conviene destacar que se han promovido las Asociaciones de Movilidad con Marruecos, Túnez y Jordania, estando en el momento presente negociándose con Líbano. El Instrumento de Asociación y Movilidad, que se puso en marcha en 2016 con una duración de treinta y cinco meses, ha servido de marco para adoptar una serie de iniciativas en este ámbito ${ }^{27}$. Por otra parte, las iniciativas regionales y bilaterales en materia de migración y movilidad en Argelia, Egipto, Libia, Marruecos y Túnez se están financiando con cargo al Fondo Fiduciario de Emergencia de la UE para África ${ }^{28}$. También conviene señalar que el Fondo Fiduciario Regional de la UE respalda diversos proyectos en Turquía y Líbano que prestan asistencia a más de siete millones de refugiados y desplazados sirios, libaneses, jordanos y palestinos $^{29}$.

Por lo que respecta a la cuestión específica del terrorismo y tras los acontecimientos del 11-S, del 11-M, del 7-J y la amenaza del Daesh, es evidente que se trata de una materia de inevitable presencia en la agenda euro-mediterránea. No obstante, conviene advertir que dada la situación que se ha vivido y se sigue viviendo en los conflictos de Afganistán, Irak y Oriente Próximo, así como la deriva impuesta por Estados Unidos en su guerra total contra el terrorismo internacional tras el 11-S, no se vislumbraron -al menos durante los primeros años- puntos importantes de convergencia en esta materia, ni siquiera en la definición de los conceptos, más allá de las declaraciones programáticas y formales de los documentos oficiales.

En efecto, a pesar de ciertos progresos parciales en la cooperación entre policías y poderes judiciales, era evidente que esta debía intensificarse en un marco que necesariamente había de superar el ámbito bilateral para situarse en el regional, creando una atmósfera de confianza que favoreciera el intercambio de información. Sin lugar a dudas, esta cuestión debe considerarse como absolutamente fundamental para afrontar con una mínima posibilidad de éxito el problema.

En esta línea de acción, la Comisión Europea, partiendo de la convicción de que esta cuestión debía enfocarse desde el pleno respeto a los derechos humanos y del diálogo político sobre las causas profundas que generan el fenómeno terrorista, propuso que los socios mediterráneos de ambas orillas abrieran un debate sobre la adopción de un Código de Conducta en Materia de Lucha Contra el Terrorismo, en particular sobre sus aspectos financieros. El Código sería finalmente adoptado en la Cumbre de Barcelona de 2005.

Puede afirmarse que la adopción del Código de Conducta puso de manifiesto la determinación de los países miembros de la AEM a utilizar todos los medios para luchar contra el fenómeno terrorista en la región mediterránea, cuestión que quedó patente en la declaración final de la Cumbre de París de julio de 2008 por la que se creó la UpM, así como en la posterior

\footnotetext{
${ }^{26}$ En la Cumbre Euromediterránea de 2005 se decidió crear un "área de cooperación mutua sobre la inmigración, la integración social, la justicia y la seguridad”, que con una entidad propia se separaba del tercer pilar al que había sido adscrita en la Declaración de Barcelona de 1995. Véase Bataller, Francisco; Jordán, Josep María: "Inmigración y relaciones euromediterráneas", ICE - Revista de Economía, no 846 (enero-febrero 2009), pp. 74 y ss.

${ }^{27}$ El Mobility Partnership Facility (MPF) es una iniciativa financiada por la UE destinada a fortalecer la cooperación entre la UE y los PSM que firmaron una Asociación de Movilidad (Jordania, Marruecos y Túnez), en https://ec.europa.eu/home-affairs/what-we-do/policies/international-affairs/global-approach-tomigration/mobility-partnership-facility_en

${ }^{28}$ EU Emergency Trust Fund for Africa, en https://ec.europa.eu/trustfundforafrica/region/north-africa_en

${ }^{29}$ Existe de forma específica un Fondo fiduciario regional de la UE en respuesta a la crisis siria, o Fondo Madad, que se destina a prestar asistencia a los refugiados y desplazados internos sirios en los países vecinos. Véase EU Regional Trust Fund in Response to Syrian Crisis, en https://eeas.europa.eu/sites/default/files/eutf_syria_factsheet-english_13112018_0.pdf
} 
reunión de ministros de Asuntos Exteriores, celebrada en Marsella en noviembre del mismo año. En ellas se hacía un llamamiento a todos los países participantes para una eficaz aplicación de dicho Código, lo que vino a demostrar que la lucha contra el terrorismo se había convertido en una de las principales prioridades del primer pilar de la Declaración de Barcelona.

La cooperación en materia política y de seguridad no ha logrado durante estos años avances espectaculares, debiendo destacarse tan solo algunos logros parciales, como la colaboración entre institutos de política exterior, así como entre responsables político-militares para las tareas humanitarias o para la elaboración de un proyecto sobre prevención de catástrofes naturales y humanas, aunque siguen sin adoptarse mecanismos efectivos que generen confianza y seguridad, principalmente para la prevención de crisis.

Estas cuestiones son objeto de estudio por la red euro-mediterránea de institutos de política exterior (EuroMeSCo), uno de los escasos logros en este primer pilar ${ }^{30}$. Otros logros destacables, aunque parciales, en este ámbito son la transformación del Foro Parlamentario Euro-mediterráneo en la Asamblea Parlamentaria Euro-mediterránea, destinada a reforzar la dimensión parlamentaria del proceso Euromed y posteriormente de la UpM, aumentando, asimismo, su visibilidad democrática.

\subsection{La cooperación económica y financiera}

En el ámbito económico, y a pesar de que se han firmado y de que han entrado en vigor los Acuerdos euro-mediterráneos con la mayoría de los países de la ribera $\operatorname{Sur}^{31}$, lo que ha contribuido a fomentar la liberalización comercial entre la UE y dichos países, conviene señalar que persisten los grandes desequilibrios y asimetrías tanto entre los PSM y la UE como en el interior de los países que conforman ambos bloques ${ }^{32}$. Es cierto que, aunque ello no debe achacarse exclusivamente al fracaso del PEM, no hay que olvidar que su progresiva reducción formaba parte de los objetivos de la Declaración de Barcelona ${ }^{33}$.

Aunque el comercio regional está aumentando en otras regiones como Asia, esta tendencia se muestra más reacia en el Mediterráneo, pues en los últimos años se observan varias tendencias complementarias: en primer lugar, se observa una cierta disminución del comercio intra-mediterráneo que ha pasado del $31 \%$ en el año 2000 al $29 \%$ en el año 2016. Aunque la mayor parte del comercio regional se da en los países mediterráneos de la eurozona $(79,4 \%$ de los flujos de importación y exportación) en los últimos años han ido perdiendo terreno frente a

\footnotetext{
${ }^{30}$ EuroMeSCo, creado en 1996, se estructura en forma de red de la que forman parte 104 instituciones de investigación y think tanks independientes de 29 países europeos y del Sur del Mediterráneo especializados en el análisis de la política exterior y la investigación sobre temas relativos a la cooperación política y la seguridad. en https://www.euromesco.net/

${ }^{31}$ Los acuerdos de asociación constituyen la base jurídica de las relaciones bilaterales de la UE con Argelia, Egipto, Israel, Jordania, Líbano, Marruecos, Autoridad Nacional Palestina y Túnez. Con Siria el acuerdo ya negociado, no llegó a firmarse tras la represión del Gobierno sirio contra las protestas ciudadanas en 2011. Con Libia, las negociaciones se suspendieron en febrero de 2011 y todavía no se han reanudado. En el momento presente Marruecos y Túnez están llevando a cabo negociaciones con la UE para un acuerdo de libre comercio de alcance amplio y profundo.

32 Todos los indicadores, relativos a tasa de pobreza, distribución de ingresos y de consumo, o prosperidad compartida, así lo constatan. Cfr. The World Bank - World Development Indicators, en https://datatopics.worldbank.org/world-development-indicators/

${ }^{33}$ La convergencia es totalmente inexistente, como lo demuestra el análisis de la evolución del PIB per cápita de los PSM en relación con la UE. Aunque algunos de los datos han cambiado considerablemente desde la primera década del presente siglo (Israel supera ampliamente a la UE: 43.592 dólares, en cambio Túnez ha caído hasta los 3.317 dólares), los datos correspondientes a 2019, según el Banco Mundial relativos al PIB per cápita (dólares USA a precios actuales) demuestran que la brecha, lejos de disminuir crece: Países MENA: 7.991 dólares (3.970 dólares, excluidos altos ingresos). UE: 34.918 dólares. https://datos.bancomundial.org/indicator/NY.GDP.PCAP.CD.
} 
los países del Mediterráneo Sur $(10,1 \%)$ y Este $(8,4 \%)$ y en menor medida los Balcanes $(2 \%)^{34}$ que, a pesar de ello, se encuentran todavía muy lejos de aquellos.

A pesar de los innegables esfuerzos de los últimos veinticinco años, el bajo nivel de integración comercial tendría su principal causa en la competencia entre los países del Sur y Este mediterráneo en los sectores agrícola y textil, aunque no es la única pues conviene poner de manifiesto que tanto la crisis de 2009 como la primavera árabe iniciada en 2011 y por supuesto la actual pandemia, han impactado negativamente en la apertura de los países de la región provocando una acusada desaceleración (con la excepción de Marruecos). Por otra parte, la superposición de acuerdos complica la relación comercial con condiciones que varían de unos a otros, observándose igualmente un incremento de medidas proteccionistas (medidas antidumping, impuestos, cuotas...) en los últimos años ${ }^{35}$. Finalmente pueden observarse nuevas tendencias en la estructura de las exportaciones de los PSM. En efecto, los países mediterráneos de la eurozona están perdiendo paulatinamente terreno en los sectores de alto valor añadido como el automovilístico o las TIC en favor de los productos agrícolas procesados y químicos, mientras que algunos de los países del Sur y Este mediterráneo están orientándose a productos de mayor valor añadido en detrimento de los sectores tradicionales como el textil ${ }^{36}$, propiciando al mismo tiempo un fortalecimiento comercial entre los países del Sur y Este mediterráneo, que, a pesar de ello, no alcanza niveles demasiado significativos aunque con una clara tendencia al alza.

Otras dificultades añadidas que ha soportado y sigue soportando el partenariado euromediterráneo vienen determinadas por la excesiva lentitud en la adopción de las necesarias reformas económicas que los diversos Acuerdos euro-mediterráneos exigen a los PSM. A pesar de que el programa MEDA y posteriormente el IEVA han intentado favorecer tales reformas, conviene advertir que la aplicación de dichos programas, en particular la primera fase del primero de ellos, no ha sido lo suficientemente ágil en muchas ocasiones por la complejidad de los procedimientos, que han presentado, no obstante, una considerable mejora en los últimos años.

La escasa cooperación comercial existente en el Sur, los todavía muy bajos niveles de inversión de la UE en la región, la deficiente infraestructura física y administrativa, así como las asimetrías y desequilibrios en las relaciones comerciales Norte-Sur, constituyen otros tantos lastres al PEM que han obstaculizado su consolidación definitiva y su conversión en un proceso más dinámico y evolutivo. La intensificación de la cooperación subregional y el fomento del comercio intrarregional constituyen factores necesarios para la creación de una zona euromediterránea de libre comercio. La constitución de zonas de comercio subregionales aceleraría, sin duda, el proceso de creación de una gran ZLC en la región. En cualquier caso, puede afirmarse que los beneficios de un incremento comercial entre los PSM no se limitarían al ámbito del comercio, sino que irían más allá al constituir un poderoso factor de atracción de la inversión extranjera, más proclive a acudir a mercados regionales que a los meramente nacionales.

Es evidente que la decisión de abrir los mercados a los intercambios entre vecinos corresponde al ámbito de la decisión política interna de cada país, pero el papel de la UE puede ser realmente importante para favorecer este proceso, no solo aportando la ayuda técnica necesaria sino también apoyando políticamente de forma más decidida los pasos que se han dado en esta dirección, como la adopción del Acuerdo de Agadir entre Egipto, Jordania, Túnez

\footnotetext{
${ }^{34}$ Cfr. Las nuevas rutas comerciales del Mediterráneo atravesarán el Sur y Este de la región, en https://www.coface.es

${ }^{35}$ Desde 2012 hasta la actualidad se han introducido 381 medidas proteccionistas netas en toda la región del Mediterráneo, de las cuales prácticamente la mitad tienen como objetivo directo otro país de la zona. Ibid.

${ }^{36}$ En particular Marruecos y Turquía (sector automovilístico), y Marruecos y Túnez (TIC).
} 
y Marruecos ${ }^{37}$, que sentaba las bases para una integración económica multilateral entre varios países mediterráneos, cuyo ejemplo ha sido seguido por otros países de la zona. Esta multiplicidad de acuerdos regionales no repercute automáticamente en una mayor y mejor integración, pues se hace necesario alcanzar un compromiso para homogeneizar, en la medida de lo posible, las reglas de origen, los estándares de calidad o los estándares fitosanitarios, entre otros.

La UE ha apoyado desde el principio el Acuerdo de Agadir, aunque conviene señalar que el nivel de comercio entre los cuatro países es todavía poco significativo debido principalmente al dominio de las barreras no arancelarias, a unas estructuras de exportación e importación muy semejantes y a la fuerte orientación del comercio hacia la UE y Estados Unidos. Por otra parte, las dificultades se centran en un marco institucional muy débil que no favorece la implantación de economías de mercado abiertas, ni las relaciones comerciales o interestatales.

Asimismo, la fragilidad institucional afecta negativamente al marco regulatorio tanto directa como indirectamente relacionado con el mercado, así como a la eficacia y transparencia de la Administración, incluida la aduanera. En cualquier caso, el potencial de complementariedad entre los países miembros del grupo Agadir parece ser muy notable, en particular entre Egipto con Jordania, Túnez y Marruecos, y entre Túnez y Jordania ${ }^{38}$.

Por lo tanto, podemos afirmar que los intercambios comerciales en la región mediterránea presentan un carácter vertical a la vez que bilateral, en la medida en que se produce de forma mucho más intensa entre la UE y cada PSM que entre estos mismos. Las causas de este reducido comercio intrarregional son diversas y podrían concretarse, además de las ya indicadas anteriormente, en la presencia de una política proteccionista muy elevada en los países de la zona, con la única excepción de Israel; en la persistencia de algunos conflictos; en la falta de complementariedad y diversificación de sus economías o en la carencia de infraestructuras de transporte. Con independencia de que algunas de estas razones podrían superarse con una voluntad política definida, no está claro que eliminando estos obstáculos el comercio intrarregional creciera rápidamente, pues la propia estructura socioeconómica de los PSM o la escasa capacidad de absorción de sus mercados podrían ralentizar considerablemente ese crecimiento.

Otra dificultad añadida viene determinada por la escasez de inversión extranjera directa (IED) en las riberas Sur y Este mediterráneas. La inversión extranjera y nacional resultan claves para el desarrollo de la región, así como para facilitar el proceso de transición económica en el que se hallan inmersos los PSM. Para mejorar el nivel de IED que se registra en la zona, es necesario proyectar una imagen más atractiva para los potenciales inversores, lo que supone acelerar una serie de medidas encaminadas a la modernización de la economía, a crear un entorno favorable a los intercambios y a la competencia, a proporcionar transparencia y seguridad en el ámbito jurídico y administrativo, o a mejorar el funcionamiento de la Administración Pública, entre otras ${ }^{39}$.

\footnotetext{
${ }^{37}$ El Acuerdo, que fue firmado el 25 de febrero de 2004 por los cuatro países y entró en vigor en el 6 de julio de 2006. en http://www.agadiragreement.org/Pages/viewpage.aspx?pageID=184

${ }^{38}$ Mahjoub, Azzam: "La Zona de Libre Comercio entre la Unión Europea y los Países Socios Árabes del Sur y Este del Mediterráneo: breve resumen de la situación y perspectivas”, Med 2009 - Anuario del Mediterráneo, Barcelona, IEMed-CIDOB, pp. 258 y 259.

${ }^{39}$ Que no son solamente de carácter aduanero, fiscal o salarial, pues los inversores valoran igualmente la talla del mercado del país y su inserción en la región, la disponibilidad y calidad de las infraestructuras o el nivel de preparación de la mano de obra y, por supuesto, el nivel de riesgo, sin ignorar la importancia de la lucha contra la corrupción. En este sentido, conviene señalar que todos los Estados de la región, excepto Siria, han ratificado la
} 
Por otra parte, y además de la intensificación del proceso de integración subregional, la necesaria estabilidad política y la resolución de los conflictos podrían revertir la tendencia que presenta el bajo nivel de IED en los PSM. Esta atonía se refleja no solo en relación con otras zonas en desarrollo, sino también en relación con la IED mundial, en particular tras el impacto de la crisis económica y financiera global de $2008^{40}$, aunque hay grandes diferencias entre los países de la región. En efecto, en el momento presente la UE sigue siendo el mayor inversionista en muchos de los PSM: en 2018 fue responsable de más de la mitad de IED en Marruecos ${ }^{41}$ y del $85 \%$ en Túnez, siendo el segundo (con un $21 \%$, por detrás del Reino Unido con un $39 \%$ ) en Egipto ${ }^{42}$.

Pese a que se observa una mejora en algunos datos como el relativo a la deuda externa de los PSM en los últimos años, otros factores como el relativo al desequilibrio en las relaciones comerciales, persisten en la región mediterránea, aunque con variaciones significativas. En efecto, las asimetrías existentes entre ambas riberas se han venido proyectando igualmente en el ámbito comercial, lo cual tampoco ha facilitado la consolidación de la AEM, dada la situación de dependencia que aquéllas generan. Dependencia del Sur respecto del Norte que se manifiesta tanto en las importaciones como en las exportaciones, lo que determina que la UE mantenga un histórico superávit comercial con los PSM, que tras unos años de relativa disminución ${ }^{43}$ volvió a repuntar con fuerza como consecuencia de la crisis económica y financiera global de $2008^{44}$.

La UE continúa siendo el principal socio comercial de los países mediterráneos, tanto por lo que respecta a las mercancías, como a los servicios. Aunque la región solo representa el $4 \%$ del mercado exterior de la UE, conviene señalar que dicho mercado es relevante para las exportaciones europeas, en particular en algunos sectores como productos industriales ${ }^{45}$, textiles o cerámica, así como para las importaciones, principalmente en los sectores energético y agroalimentario. En 2019 el intercambio comercial entre la UE y los PSM ascendió a 150.000 millones de euros en productos industriales y a 15.000 millones en productos agrícolas, siendo

\footnotetext{
Convención de las Naciones Unidas contra la Corrupción, aunque la situación de ésta se ha deteriorado notablemente en Líbano, Egipto, Siria y Libia.

${ }^{40}$ Según estimaciones del Banco Mundial y tomado como referencia los países de Oriente Medio y Norte de África, el máximo de IED se obtuvo en 2007 con 126.452 millones de dólares, empezando un descenso acentuado a partir de esa fecha y coincidiendo con la crisis de 2008, hasta tocar fondo en 2014 con 37.333 millones de dólares. A partir de esa fecha empezó de nuevo a ascender hasta alcanzar los 60.078 millones de dólares en 2018, produciéndose un leve descenso en 2019 con 58.313 millones de dólares. Entre los PSM destacan en ese año Israel con 19.047 millones de dólares, Egipto con 9.010, Líbano con 2.223 y Marruecos con 1.599. Cfr. Banco Mundial - IED en Medio Oriente y Norte de África, en https://datos.bancomundial.org/indicador/BX.KLT.DINV.CD.WD?locations=ZQ.

${ }^{41}$ En 2018 Marruecos atrajo 3.600 millones de dólares, un 36\% más que en 2017. Los principales inversores fueron países de la UE: Irlanda con un 20\% del total, Francia con un 17\%, Dinamarca con un $7 \%$ y España con un $6 \%$. No obstante, los Emiratos Árabes Unidos ocuparon el tercer lugar con un 8,2\%. Los principales sectores que atrajeron en ese año la IED fueron los seguros con un $21 \%$ y la industria manufacturera con un 18,2\%. Entre dos orillas, Atalayar, en https://atalayar.com/content/la-llegada-de-ied-marruecos-aument\%C3\%B3-un-36-en-2018

${ }^{42}$ Informe de la Comisión al Parlamento Europeo, al Consejo, al Comité Económico y Social Europeo y al Comité de las Regiones sobre la aplicación de los Tratados de Libre Comercio, COM(2020)705 final, Bruselas, 12.11.2020, p. 25.

${ }^{43}$ Debido al proceso de liberalización progresiva del comercio con la UE que ha requerido llevar a cabo reformas estructurales, así como al incremento de los precios de los productos energéticos.

${ }^{44}$ en http://trade.ec.europa.eu/.

${ }^{45}$ La mayoría de los productos industriales están libres de derechos de aduana entre la UE y los PSM. Egipto culminó su proceso de desmantelamiento de aranceles el 1 de enero de 2019 con la eliminación de los aranceles sobre las exportaciones de automóviles. Tan solo Siria aplazó el desmantelamiento de varios productos industriales sobre los que han continuado los aranceles, pero con un tipo bajo, hasta septiembre de 2020. Informe de la Comisión al Parlamento Europeo, al Consejo, al Comité Económico y Social Europeo y al Comité de las Regiones sobre la aplicación de los Tratados de Libre Comercio..., op. cit., p. 23.
} 
Marruecos, Israel, Egipto y Argelia los principales mercados para las exportaciones de la UE en la región ${ }^{46}$.

El empeño de la UE en favorecer el desarrollo de la región y en promover la superación de los problemas estructurales, creando al mismo tiempo sistemas productivos más sólidos, más competitivos y más diversificados, no ha provocado los resultados esperados a pesar de los considerables recursos aportados por la Unión ${ }^{47}$. A pesar de que la UE continúa siendo el principal socio comercial de los PSM, una de las primeras fuentes de asistencia, cooperación financiera e IED, así como principal destino de los movimientos migratorios procedentes del Sur, no se ha de ignorar que su posición sufre el riesgo de sucumbir a la imparable penetración de China en la zona donde, por ahora, se ha convertido en el principal socio comercial de Argelia pero que en un futuro podría serlo igualmente para el resto de PSM si la UE no adopta medidas urgentes y estratégicas para impedirlo.

\subsection{La cooperación social, cultural y humana}

Tampoco se han producido avances significativos en el ámbito del llamado tercer "cesto", cooperación social, cultural y humana, en particular en los sectores del diálogo intercultural y de los intercambios humanos.

Los firmantes de la Declaración de Barcelona se comprometieron a potenciar el conocimiento mutuo y el diálogo intercultural, así como los intercambios humanos, científicos y tecnológicos, desde el convencimiento de que estos favorecen el acercamiento y la mutua comprensión entre los pueblos. En esta línea de pensamiento, la Conferencia de Barcelona decidió establecer una asociación en los ámbitos social, cultural y humano con el fin último de aproximar los pueblos y las culturas, así como de mejorar la percepción mutua entre las dos riberas mediterráneas.

Para la consecución de tales objetivos, el Programa de Trabajo adoptado al efecto identificaba dos líneas prioritarias de acción: por un lado, el fomento del diálogo entre culturas y civilizaciones con el fin último de combatir la intolerancia y el fanatismo; y, por otro lado, potenciando la interacción entre los medios de comunicación. Todos estos objetivos y líneas de acción han sido ratificados y confirmados en los diferentes encuentros y conferencias ministeriales desarrollados hasta el momento presente.

En el ámbito específico de la cooperación cultural ${ }^{48}$, el balance de los años transcurridos desde la Conferencia de Barcelona, permite constatar un relativo progreso que se concreta con la adopción de una serie de programas regionales: "Euromed Heritage", destinado a la conservación del patrimonio cultural euro-mediterráneo, en sus cuatro ediciones, el programa "Euromed Audiovisual", destinado a fomentar la cooperación euro-mediterránea en el sector audiovisual, la extensión del programa de enseñanza superior "Tempus" a los PSM, posteriormente integrado en el Programa Erasmus +, así como el programa "Euromed Juventud"

\footnotetext{
${ }^{46}$ Marruecos con un 23\%, Israel con un 20\%, Egipto con un $19 \%$ y Argelia con un $17 \%$. Del total de productos exportados por la UE a los PSM en 2019, el 90\% son industriales (sector energético y productos manufacturados) quedando todavía margen para la liberalización de las exportaciones agrícolas, en particular a Túnez y Argelia, ibid., pp. 24 y 25.

${ }^{47}$ Desde 2007 hasta 2020, la UE ha destinado 20.500 millones de euros a la cooperación en la vecindad meridional a través de sus sucesivos instrumentos financieros de vecindad europea. Política Europea de Vecindad, en https://ec.europa.eu/neighbourhood-enlargement/neighbourhood/southern-neighbourhood_en.

${ }^{48}$ Sobre esta cuestión véase Marquina, Antonio: "La cooperación social, cultural y humana en el Mediterráneo" y Solera, Gianluca: "La cooperación cultural en el espacio mediterráneo: apuntes para un decálogo", en Beneyto, José María; Sorroza Blanca, Alicia (eds.) (2010): La apuesta por el Mediterráneo. Un reto para el siglo XXI, Madrid, Instituto Universitario de Estudios Europeos - Universidad CEU San Pablo, pp. 121-129 y 143-158, respectivamente.
} 
destinado a la formación específica e intercambios de este sector que representa un alto porcentaje de la población en los PSM.

Por otra parte, debe destacarse en este ámbito la creación de la Fundación Euromediterránea "Anna Lindh", que con sede en Alejandría, desempeña un papel importante en la promoción del diálogo entre las culturas y civilizaciones ${ }^{49}$, así como ciertas acciones del Programa Meda-Democracia, y con posterioridad la Iniciativa Europea para la Democracia y los Derechos Humanos, que han venido apoyando la independencia de los medios de comunicación y la libertad de prensa, así como los derechos de la mujer y la igualdad de género.

La cooperación entre las sociedades civiles de las dos riberas mediterráneas durante estos años, ha sido activada principalmente gracias a los programas de cooperación bilaterales, entre socios, y birregionales, financiados por la Comisión Europea. Estos programas se han destinado a potenciar la cooperación entre las sociedades civiles y, aunque no representan más que una pequeña parte de la cooperación euro-mediterránea, han constituido un elemento importante de las relaciones entre ambas riberas mediterráneas. Por otra parte, procede hacer notar que la cooperación en este tercer pilar ha utilizado los mismos mecanismos e instrumentos de trabajo que los demás pilares del PEM, siendo destacables, además de los programas de cooperación mencionados, los compromisos políticos adoptados por medio de las declaraciones de los ministros en las reuniones generales o sectoriales.

A título de balance del tercer "cesto", podemos afirmar que los progresos realizados en el sector de la cooperación social, cultural y humana son modestos, pues aunque se hayan logrado algunos avances parciales, como la puesta en marcha de programas de cooperación regionales y bilaterales o la adopción de acciones específicas en el ámbito de la cooperación cultural $^{50}$ y entre la sociedad civil, los avances son mínimos en otras materias como la circulación de personas por el espacio mediterráneo o la protección de las minorías. Es más, puede sostenerse que uno de los sectores en que ha habido más progresos es precisamente el que se refiere a la cooperación en materia de persecución del narcotráfico, crimen organizado y en general en las materias de justicia, seguridad y migración, en las que la existencia de intereses compartidos, como la cooperación policial y judicial contra la inmigración irregular, ha generado unos niveles más notables de convergencia de intereses entre la UE y los PSM ${ }^{51}$.

Ciertamente, el propio diseño del cesto vaticinaba su escaso éxito dado que se proyectó desde una perspectiva eurocéntrica carente de aportaciones de los PSM por lo que no deja de resultar paradójico que se trate de temas que, como ya advertimos, se hallaban integrados formalmente en este tercer cesto pero que guardan una relación directa con el primero, en la medida en que dicha cooperación es política y se concibe en muchas ocasiones desde la óptica de la seguridad, lo que ha desvirtuado los verdaderos objetivos de este tercer cesto incorporados a la Declaración de Barcelona.

\footnotetext{
${ }^{49}$ Nicolaïdis, Dimitri: “Creación de la Fundación Euromediterránea para el Diálogo entre las Culturas y las Civilizaciones", y Gillespie, Richard: "Cultura, comunidad y la Fundación Euromediterránea", ambos en Med 2003 - Anuario del Mediterráneo, Barcelona, IEMed-CIDOB, pp. 92-93 y 234-236, respectivamente. Actualmente, la Fundación, que funciona desde 2005, aglutina a más de 4.500 organizaciones de la sociedad civil pertenecientes a los 43 países miembros de la UpM (asociaciones, ONGs, universidades, instituciones públicas y privadas...), en https://www.annalindhfoundation.org/about

${ }^{50}$ Véase al efecto Balta, Paul: "El diálogo cultural en el Partenariado Euromediterráneo (PEM)", Med 2009 Anuario del Mediterráneo, IEMed-CIDOB, Barcelona, 2009, pp. 316-322.

${ }^{51}$ Barbé, Esther: "La Unión por el Mediterráneo: de la europeización de la política exterior a la descomunitarización de la política mediterránea”, Revista de Derecho Comunitario Europeo, (enero/abril 2009), p. 25.
} 


\section{La Política Europea de Vecindad}

La PEV, instaurada en 2004, se define como una política unilateral nacida en el seno de las instituciones europeas, que sin embargo precisa de la implicación activa de los PSM a los cuales va dirigida a través de la copropiedad o joint ownership. De ahí proviene la importancia no solamente de incluir a los socios sino también de asumir la propia UE el concepto de diferenciación en la progresiva implementación. En función de lo cual desde el momento de la articulación de la PEV ya se observó que podría ser objeto de sucesivas revisiones con el fin de adaptarse a las circunstancias sobrevenidas tanto en la orilla Norte como en la Sur. En definitiva, la PEV busca incrementar el grado de integración de los beneficiarios respecto a las políticas y al mercado interior, de tal forma que a mayor cooperación y avance de las reformas en sectores clave, los países vecinos obtendrían mayores beneficios y en particular una mayor profundización en las relaciones comerciales. Por consiguiente, nos encontramos ante el principio de condicionalidad positiva o "más por más" 52 , abandonándose de esta forma la dimensión negativa que caracterizaba el Proceso de Barcelona.

\subsection{La revisión de la $P E V$ a tenor de la primavera árabe}

La posibilidad de enfocar la cooperación con los Estados vecinos de una forma más integrada, que ofrecía el Tratado de Lisboa, permitió que solo unos meses más tarde de su entrada en vigor se planteara la conveniencia de reconsiderar la PEV. Posteriormente y con los acontecimientos acaecidos en el mundo árabe desde principios de 2011, se generó en la UE la necesidad de reorientar el enfoque de las relaciones euro-mediterráneas existentes hasta el momento y de forma particular la PEV, con el objetivo de afrontar los retos derivados de la nueva situación que se estaba generando en el vecindario Sur y Este mediterráneos.

A tal efecto, la Comisión Europea y la Alta Representante de la UE para la Política Exterior, presentaron una Comunicación conjunta el 25 de mayo de 2011, con el título: "Una nueva respuesta a una vecindad cambiante" ${ }^{, 53}$. En dicho documento se ponía de manifiesto la necesidad de adoptar un nuevo enfoque basado en un compromiso compartido con los países vecinos respecto a los valores universales de la democracia, el Estado de Derecho y los derechos humanos. Esta nueva orientación exigía aplicar de una forma mucho más rigurosa el principio de diferenciación de tal forma que los vínculos de cada país vecino con la UE dependieran directamente de las aspiraciones, capacidades y necesidades de cada uno de ellos, así como de los resultados obtenidos en el proceso de reformas políticas y económicas emprendidas. Cuantos mayores fueran los resultados obtenidos, mayor sería también el grado de integración económica y de cooperación política que ofreciera la UE a cada uno de sus vecinos.

La UE pretendía con el nuevo enfoque de la PEV, conceder un mayor apoyo a dichos países para la consecución de una democracia viable y sólida, basada en el pluripartidismo y en unas elecciones libres y transparentes, en una división real de poderes que incluyera un poder judicial fuerte e independiente, en el respeto a los derechos humanos y a las libertades fundamentales, así como en una Administración pública eficaz y transparente. El apoyo de la UE a los países vecinos debía enfocarse asimismo a la consecución de otros dos objetivos: por un lado, el logro de un desarrollo económico y un crecimiento sostenible capaz de reducir las enormes desigualdades sociales y regionales existentes, y por otro lado, la mejora de los sistemas de sanidad y educación.

La revisión de la PEV que propusieron conjuntamente la Comisión Europea y la Alta Representante, se basaba igualmente en el principio de condicionalidad, que debía regir las

\footnotetext{
${ }^{52}$ Tovias, Alfred: “La condicionalidad y la política europea de Vecindad”, Cuadernos Económicos: ICE, $\mathrm{n}^{\circ} 846$ (enero-febrero 2009), pp. 7-17.

${ }^{53}$ Una nueva respuesta a una vecindad cambiante, $\operatorname{COM}(2011) 303$ final. Bruselas, 25.5.2011.
} 
relaciones bilaterales, en la medida en que la ayuda de la UE a dichos países dependería directamente de los progresos obtenidos en el proceso de reformas tanto políticas, en particular la consolidación de la democracia y del Estado de Derecho, como económicas ${ }^{54}$. De esta forma la UE prestaría mayor apoyo a aquellos vecinos que más hubieran avanzado en este proceso reformador, apoyo que se materializaría en una mayor financiación que permitiera más desarrollo económico y social, una mayor facilitación de la movilidad, un aumento de la financiación del BEI en apoyo a las inversiones y un mayor acceso a los mercados comunitarios.

Las reformas adoptadas en el período 2010-2012, reflejadas en los informes de situación anuales, se tomarían como referencia para decidir las asignaciones financieras nacionales para 2014 y años sucesivos. El principio de condicionalidad debería operar igualmente en sentido inverso, es decir penalizando, incluso con la reducción de la financiación, a aquellos países vecinos que no hubieran avanzado en el proceso de reformas, tomando medidas adicionales, como sanciones selectivas, respecto de aquellos que violaran los derechos humanos y las normas básicas democráticas ${ }^{55}$.

El apoyo financiero de la UE a los países vecinos en su transición a una democracia viable y sólida, incluiría el refuerzo a los agentes, como partidos políticos, ONGs o sindicatos, que luchan por su consecución, a través del establecimiento de una Dotación Europea para la Democracia y de un Mecanismo de Vecindad para la Sociedad Civil, además del ya existente Instrumento Europeo para la Democracia y los Derechos Humanos. El nuevo enfoque de la PEV debía prestar una atención preferente a la consecución en los países de la vecindad, de un crecimiento económico firme y sostenible, para lo cual es indispensable la ayuda al entorno empresarial, en particular a las pymes, a la creación de empleo y al fomento de la IED, así como a la transferencia de tecnología, cuestiones que sin duda se verían favorecidas con la transición política hacia una democracia estable.

La nueva PEV debía asimismo reforzar los vínculos comerciales con los países vecinos principalmente a través de la creación de zonas de libre comercio exhaustivas, que implicarían no solo el desmantelamiento progresivo de las barreras comerciales y de los derechos de importación, sino también la convergencia reglamentaria en sectores como las normas sanitarias y fitosanitarias, los procedimientos aduaneros, la contratación pública, la competencia y la protección de las inversiones. El mayor acceso a los mercados de bienes podría potenciarse a través de acuerdos sobre evaluación de la conformidad y aceptación de los productos industriales, que facilitarían el reconocimiento mutuo de los certificados de conformidad. Con el objetivo de apoyar el proceso de reformas, la UE debía seguir ofreciendo el asesoramiento de expertos a través de los programas de desarrollo institucional o de otros mecanismos como los programas de hermanamiento y el TAIEX ${ }^{56}$.

La profundización de la cooperación sectorial debía estar igualmente en el punto de mira de la nueva PEV. Aunque la cooperación podría extenderse a toda una serie de sectores relativos a las cuestiones de cooperación política y de seguridad, protección de los consumidores, salud pública, investigación y desarrollo tecnológicos, turismo, política social, derecho de las sociedades o política marítima, entre otros, debería focalizarse de una forma particular en una serie de sectores como la energía, el transporte, la protección del medioambiente y la lucha

\footnotetext{
${ }^{54}$ En cualquier caso, la aplicación del principio de condicionalidad debería ser más efectiva y condicionada al respeto del Estado de Derecho. Cfr. Tocci, Nathalie; Cassarino, Jean-Pierre: "Rethinking the EU's Mediterranean Policies Post 1/11", Istituto Affari Internazionali (IAI) Working Papers, vol. 11, no 6 (marzo 2011), pp. 17-19.

${ }^{55}$ Ibid., p. 3.

${ }^{56}$ Gestionado por la Comisión, TAIEX constituye un instrumento de asistencia y asesoramiento técnico específico e intercambio de información que apoya a los países socios en lo relativo a la aproximación, aplicación y ejecución de la legislación de la UE. Cfr. en http://ec.europa.eu/enlargement/taiex/what-is-taiex/index_en.htm
} 
contra el cambio climático, el espacio común del conocimiento, la enseñanza superior, la investigación y la innovación.

La revisión de la PEV debía incluir asimismo un replanteamiento de las cuestiones de la migración y de la movilidad, de tal forma que resultara beneficioso para ambas partes e integraran una serie de factores como la gestión adecuada de la migración legal y de las fronteras, el asilo o el desarrollo económico ${ }^{57}$. El marco para garantizar que la circulación de personas entre la UE y un tercer país estaba bien gestionada lo proporcionarían las asociaciones de movilidad, al incorporar una serie de medidas como un mejor acceso a los canales de migración legal, y una serie de iniciativas para mejorar la gestión de las fronteras y de la migración irregular.

Con independencia de que ya se habían establecido asociaciones de movilidad con algunos países de la vecindad oriental, como Moldova y Georgia, o de la que se estaba a punto de concluir con Armenia, la Comisión, de conformidad con la "Comunicación sobre un diálogo para la migración, la movilidad y la seguridad con los países del Mediterráneo Meridional”58 se comprometía a iniciar negociaciones con Marruecos, Túnez y Egipto ${ }^{59}$. Con el objetivo de mejorar la movilidad de estudiantes, investigadores y empresarios, e incluso de expedir visados de entrada múltiple para estos colectivos, la Comisión instaba a los Estados miembros a utilizar todas las posibilidades que ofrece el código de visados de la UE. En cuanto al asilo, la aplicación del Programa de Protección Regional, que ya se utilizaba para Belarús, Moldova y Ucrania, se extendería a Egipto, Libia y Túnez, cuando las circunstancias lo permitieran ${ }^{60}$.

El nuevo enfoque de la PEV debía reforzar de forma decidida sus dimensiones regionales, la Asociación Oriental y el Mediterráneo Meridional, con el objetivo de desarrollar proyectos de cooperación regionales y viables en los ámbitos del comercio, el transporte, la energía, la movilidad o la migración, así como responder a los específicos retos de cada región en los ámbitos políticos, geográficos, económicos y sociales ${ }^{61}$.

Por lo que respecta al Mediterráneo Meridional, objeto de nuestra atención específica en este trabajo, la Comisión Europea y la Alta Representante ya habían adoptado una Comunicación conjunta en la que exponían las orientaciones generales que debían regir el proceso de revisión de la política mediterránea de la UE, que partiría con la creación de una "Asociación para la democracia y la prosperidad compartida con los países del Mediterráneo Meridional"62.

La nueva asociación, que como ya advertimos estaría más orientada a las necesidades concretas y al nivel de ambición en el proceso de reformas demostrado por cada socio, podría ampliar la concesión del Estatuto Avanzado, ya concedido a Marruecos en 2008 y a Jordania en 2010, a otros países que demostrasen igual disposición y compromiso con las reformas. La concesión del Estatuto, que se basa en un Plan de Acción nuevo y más global, podría implicar un refuerzo a la cooperación política y de seguridad, un incremento de las concesiones comerciales y una mayor integración en el mercado interior de la UE, así como un mayor apoyo financiero a las reformas.

\footnotetext{
${ }^{57}$ De conformidad con la Comunicación sobre migración, COM(2011)248 final, Bruselas, 04.05.2011.

${ }^{58}$ Comunicación sobre un diálogo para la migración, la movilidad y la seguridad con los países del Mediterráneo Meridional, COM(2011)292/3.

${ }^{59}$ Como paso previo a la asociación de movilidad, la Comisión pondrá en marcha un diálogo en materia de migración, movilidad y seguridad con tales países.

${ }^{60}$ Una nueva respuesta..., op. cit., pp. 14 y 15.

${ }^{61}$ La potenciación de la cooperación regional es compatible con el refuerzo de la cooperación subregional, centrada en temas más específicos y con la participación más limitada de países. Un ejemplo lo podría constituir la cooperación subregional en el Magreb, que podría centrarse en el apoyo a una mayor interconexión física.

62 Asociación para la democracia y la prosperidad compartida con los países del Mediterráneo Meridional, COM(2011)200 final, Bruselas, 08.03.2011.
} 
Con el objetivo de apoyar la transformación democrática y dar respuesta a los nuevos retos planteados tras los recientes acontecimientos que habían acaecido en el Mediterráneo meridional, se establecerían Programas Globales de Desarrollo Institucional, similares a los ya aplicados con los vecinos orientales, que proporcionarían asesoramiento y apoyo financiero para desarrollar la capacidad de aquellos organismos que se consideraran claves para consolidar el proceso de transición a la democracia. Con el fin de crear una asociación más fuerte con las personas, segundo pilar en el que debía basarse la nueva asociación, la Comisión pondría en marcha, como ya advertimos, un diálogo en materia de migración, movilidad y seguridad con Marruecos, Túnez y Egipto, previo al establecimiento de una asociación de movilidad, y potenciaría los programas dirigidos a los jóvenes.

Finalmente, y en relación con el tercer pilar en el que debía basarse la nueva asociación -el desarrollo económico sostenible e integrador- la UE debería intensificar sus esfuerzos para mejorar las disposiciones comerciales de los Acuerdos de Asociación y finalizar las negociaciones, en aquel momento en marcha, sobre la agricultura, servicios y derecho de establecimiento, ofreciendo a aquellos vecinos del Sur que hubieran realizado más rápidamente las reformas necesarias, la posibilidad de establecer zonas de libre comercio exhaustivas y profundas Con el fin de prestar apoyo a las reformas estructurales que serían necesarias a tal efecto, la Comisión financiaría programas de desarrollo agrícola y rural, promovería la cooperación industrial a escala euro-mediterránea, con la aplicación de la Carta Euromediterránea de la Empresa, en particular entre las pymes, y fomentaría igualmente el diálogo sobre el empleo y la política social mediante el Foro de Diálogo Social Euro-mediterráneo.

El nuevo enfoque de la PEV fue planteado conjuntamente por la Comisión y la Alta Representante en un momento en el que una parte de los vecinos del Sur se hallaban en un proceso de transformación, pero también de convulsión sin precedentes. Las propuestas, que deberían ser respaldadas por el Parlamento Europeo y el Consejo, pretendían dar respuesta adecuada a las nuevas necesidades surgidas en el vecindario Este, pero sobre todo Sur, que configuraban un total de ochocientos millones de personas, cuya libertad, seguridad y desarrollo merecen ser compartidas, lo que sin lugar a dudas redundaría en el reforzamiento de los intereses de la propia Unión.

En definitiva, el rediseño de la PEV debía orientarse no solo a ofrecer más incentivos y beneficios a los vecinos, sino también y principalmente a cambiar el sentido de las relaciones de la UE con tales países. Para ello, algunos autores como Grant ${ }^{63}$ identificaron los grandes vectores en los que debía proyectarse la reforma de la PEV: profundización del principio de diferenciación; cambios radicales en la UpM transformándola en una plataforma menos política y mas tecnocrática; más condicionalidad positiva; mayor énfasis en la democracia y en los derechos humanos; una orientación más política de la PEV y mensajes más consistentes por parte de la UE.

\subsection{La oportunidad de una nueva revisión de la PEV en 2015.}

La cambiante situación en el vecindario Este y Sur, determinaron la conveniencia por parte de la Comisión de plantear una nueva revisión de la PEV en 2015. En efecto, en marzo de dicho año, la Comisión y la Alta Representante publicaron conjuntamente un Documento Conjunto de Consulta, con el título "Hacia una nueva Política Europea de Vecindad"64, que planteaba un proceso de consulta para volver a revisar la PEV, invitando a todos los actores implicados (Estados miembros, Estados vecinos, sociedad civil...) a aportar sus puntos de vista sobre la

\footnotetext{
${ }^{63}$ Grant, Charles: "A new neighbourhood policy for the EU”, Policy Brief - Centre for European Reform, (marzo 2011), pp. 9 y ss.

${ }^{64}$ Hacia una Nueva Política de Vecindad, JOIN(2015)6 final, Bruselas, 04.03.2015.
} 
misma. En noviembre de ese mismo año de 2015 se publicó por sus mismos inspiradores una Comunicación sobre los resultados de la consulta ${ }^{65}$.

Con el fin de realizar un seguimiento de la aplicación de la revisión de la PEV, la Comisión y la Alta Representante publicaron un informe conjunto 18 de mayo de $2017^{66}$, que recoge las prioridades políticas generales acordadas con el Consejo ${ }^{67}$ tras la publicación en 2016 de la Estrategia Global de la UE para la Política Exterior y de Seguridad ${ }^{68}$. La nueva PEV revisada pretende lograr una aproximación más eficaz a los ámbitos de interés mutuo, respetando al mismo tiempo las distintas aspiraciones de los socios de la UE, para lo cual introduce nuevos métodos con el fin de lograr una mayor implicación de los Estados miembros aplicando, asimismo, una mayor flexibilidad en la forma en que la UE desarrolla sus políticas.

El informe destaca el modo en que la UE y sus vecinos del Este y del Sur trabajan para lograr una mayor estabilización y capacidad de adaptación centrándose principalmente en el desarrollo económico, en el empleo juvenil y el compromiso de la UE en promover la democracia, el Estado de Derecho, la protección de los derechos humanos y la buena gobernanza potenciando asimismo la participación de la sociedad civil.

A partir de 2016 se establecieron nuevos marcos para las relaciones bilaterales a través de las prioridades de asociación ${ }^{69}$, las agendas de asociación actualizadas o los planes de acción ya existentes, que pretenden reflejar el nivel de ambición de cada socio en sus relaciones con la UE. Estos documentos bilaterales conjuntos reflejan las prioridades políticas compartidas y han sentado las bases para los nuevos programas de asistencia bilateral.

En definitiva, se trata de determinar las prioridades a corto y medio plazo, estableciendo programas de reforma política y económica de conformidad con las necesidades e intereses de los países vecinos. En particular, se pretende transitar hacia sociedades democráticas y socialmente equitativas, fomentar la integración económica, potenciar la educación, impulsar las pymes, así como la agricultura y facilitar los movimientos transfronterizos de personas.

Por lo que respecta a las relaciones regionales, el informe destaca los progresos alcanzados en el marco de la Asociación Oriental con los vecinos del Este, y de la UpM en relación con la vecindad Sur, así como con otros actores como la Liga de Estados Árabes o la Conferencia de Cooperación Islámica, entre otros.

En cuanto a la financiación de estos planes y programas se lleva a cabo con cargo al Instrumento Europeo de Vecindad (IEV) ${ }^{70}$ que se integrará en el futuro Instrumento de

\footnotetext{
${ }^{65}$ Unos meses antes, el 9 de julio de ese mismo año, el Parlamento Europeo aprobó una Resolución en la que abogaba por una PEV más estratégica, flexible y coherente, en

https://www.europarl.europa.eu/doceo/document/TA-8-2015-0272_ES.html

${ }^{66}$ Informe sobre la aplicación de la Revisión de la Política Europea de Vecindad, JOIN(2017)18 final, Bruselas, 18.05.2017.

${ }^{67}$ Conclusiones del Consejo relativas a la Estrategia Global sobre Política Exterior y de Seguridad de la Unión Europea (doc. 13202/16, de 17 de octubre de 2016), en https://data.consilium.europa.eu/doc/document/ST-132022016-INIT/es/pdf

${ }^{68}$ Sobre esta cuestión, puede verse Nieto, María Isabel (coord.) (2020): La UE y el Mediterráneo a la luz de la Estrategia Global de Seguridad de la Unión. Retos futuros en las políticas de vecindad, seguridad y defensa, Madrid, Dykinson. Sobre el tema específico de la PEV, véase de la misma autora, "La Política Europea de Vecindad en un mundo frágil y en tiempos de pandemia", ibid. pp. 63-106.

${ }^{69}$ En 2016 se aprobaron las prioridades de asociación con Líbano, Jordania y Egipto, y en 2017 con Argelia. Asimismo, se intensificaron las formas de cooperación con Túnez y Marruecos.

${ }^{70}$ El IEV tenía una dotación de 15.400 millones de euros para el período 2014-2020. La gran mayoría de estos fondos se han canalizado de forma bilateral para financiar las reformas y prioridades plasmadas de mutuo acuerdo en sus respectivos Planes de Acción. El IEV ha financiado igualmente programas regionales en el Este y en el Sur, programas de cooperación transfronteriza y programas de cooperación institucional para toda la vecindad como los hermanamientos o la asistencia e intercambio de información (TAIEX).
} 
Vecindad, Desarrollo y Cooperación Internacional ${ }^{71}$. Por otra parte, el Banco Europeo de Inversiones y el Banco Europeo de Reconstrucción y Desarrollo completan de una forma flexible la financiación de aquéllos a través de préstamos.

Aprovechando los debates sobre el nuevo marco financiero plurianual para el período 2021-2027 se revisó la arquitectura y el funcionamiento de los instrumentos de financiación exterior de la UE, entre ellos el IEV. A tal efecto el Parlamento Europeo aprobó un informe sobre dicha propuesta ${ }^{72}$ en el que solicita un incremento de la financiación, así como la suspensión de la ayuda en caso de violación de los derechos humanos y la sustitución del enfoque basado en los incentivos por un nuevo enfoque basado en los resultados en lo relativo a las relaciones de vecindad.

Desde su lanzamiento la PEV ha suscitado numerosos interrogantes y dudas no solo en el mundo académico si no también y de forma destacada entre los propios PSM, que le han reprochado a menudo su indefinición, así como la falta de objetivos concretos y bien delimitados. El hecho de que su propia gestación fuera consecuencia directa de una profunda reflexión de cómo serían las relaciones futuras entre la UE y los nuevos países fronterizos del Este tras las sucesivas fases de ampliación, y de que tan solo en un fase posterior se decidiera incluir a los PSM en la nueva iniciativa, parecía indicar que en el "inconsciente comunitario" primaba la relación con el Este en detrimento del Sur, quizás por la convicción no declarada de que aquéllos estaban en disposición de avanzar más rápidamente en las reformas tanto políticas como económicas que la nueva PEV implicaba.

Por otra parte, la inclusión en la nueva PEV de dos grupos en principio tan heterogéneos como el Este europeo y el Sur mediterráneo sin tener en cuenta el "acervo" de las relaciones euro-mediterráneas de larga data, ha tenido como consecuencia una cierta pérdida de la identidad mediterránea que se ha visto diluida en la nueva iniciativa en la que los PSM deben rivalizar con los del Este, sin pertenecer, como la mayoría de éstos, al mismo espacio geográfico e incluso geoestratégico europeo. Esta circunstancia les confiere una ventaja de partida frente a los PSM, en la medida en que, al menos en principio, no puede descartarse definitivamente su adhesión a la UE, por muy lejana e improbable que esta pueda llegar a parecer en el caso de que realmente se produzca en un futuro.

El hecho de que la PEV se diseñara para aquellos países que no tienen expectativas de adhesión, no ha comportado que fuera recibida por estos con entusiasmo, ya que en ningún caso la han considerado como un sustitutivo de la plena integración al percibirla como una oferta sensiblemente menor a esta. El caso específico de Marruecos, siempre dispuesto a demostrar su singularidad en el trato con la UE -que se ha materializado a través del Estatuto avanzado en 2008- ilustraría esta actitud no entusiasta, de cautela y un tanto fría de los PSM ante la PEV. Ciertamente esta fue una iniciativa de la UE que no solicitaron los vecinos y cuya lógica no han llegado a entender bien los destinatarios, en particular los PSM.

Desde esta perspectiva la PEV parece estar inspirada, aunque no se presenta lógicamente de esta forma, por un interés propio y específico, diríamos unilateral de la UE, en conseguir una vecindad estable y a ser posible próspera que garantice su seguridad, a través de

\footnotetext{
${ }^{71}$ Propuesta de Reglamento del Parlamento Europeo y del Consejo por el que se establece el Instrumento de Vecindad, Desarrollo y Cooperación Internacional, COM(2018)460 final, Bruselas, 14.06.2018.

${ }^{72}$ Resolución legislativa del Parlamento Europeo de 27 de marzo de 2019, sobre la propuesta de Reglamento del PE y del Consejo por el que se establece el Instrumento de Vecindad, Desarrollo y Cooperación Internacional, en https://www.europarl.europa.eu/doceo/document/TA-8-2019-0298_ES.html\#title2. El nuevo Instrumento de Vecindad, Desarrollo y Cooperación Internacional tiene asignada una dotación financiera de 79.462 millones de euros para el período 2021-2027 y proporcionará financiación a través de tres pilares clave: geográfico (60.388 millones de los que al menos 19.323 se destinarán a la vecindad manteniendo un equilibrio geográfico adecuado); temático (6.358 millones) y respuesta rápida (3.182 millones).
} 
la "exportación" de sus valores e intereses, los cuales pretende presentar a los vecinos como compartidos. Al mismo tiempo, va a ser la capacidad de los vecinos para adoptar las reformas necesarias y lograr dicho standard la que determine el nivel de los beneficios obtenidos. Esta situación respondería a una política de dominio de la UE hacia sus vecinos que, en el marco de una asimetría evidente de poder, caracterizaría a aquélla como una especie de "hegemonía normativo regional" $" 73$.

En efecto, la UE ofrece a los vecinos un mayor acceso al mercado comunitario, que posibilite un mayor crecimiento económico a través de un proceso de modernización y de reformas políticas y económicas conducente a una zona de estabilidad y de codesarrollo. La propia dinámica de funcionamiento de la PEV diseñada por la UE, ha obligado a cada país vecino interesado en participar en la misma, a comprometerse a través de acuerdos para llevar a cabo una serie de reformas en una amplia y diversificada serie de sectores que van desde el diálogo político, el desarrollo económico y social, las cuestiones comerciales, la cooperación regional o los transportes, la energía y el medio ambiente, entre otros. Es cierto que la UE se compromete a aportar apoyo financiero y técnico para que los vecinos puedan poner en marcha los procesos de reforma, pero también lo es que la UE se reserva el derecho a "discriminarlos" en función de los objetivos alcanzados.

Este enfoque plantea al menos dos tipos de efectos que pueden llegar a ser contradictorios entre si. Por una parte, con su voluntarismo intervencionista, la UE al "premiar" a los socios que demuestren su eficacia reformista en los ámbitos político, económico o institucional y de alguna forma, "castigar" a aquellos que no logren alcanzar un mínimo nivel reformista, se coloca no solo en una posición paternalista, siempre denostada por los socios mediterráneos, sino también en una situación que le permite menos campo de acción que otros actores internacionales cada vez más presentes en la región. Entre ellos conviene destacar a China, que en ningún caso exige cambios en el orden normativo interno ni por supuesto compromisos en los ámbitos de los derechos humanos, la buena gobernanza o la economía de mercado, a cambio de cooperación ${ }^{74}$.

Sin embargo, ante el argumento de la pretendida superioridad moral de la actuación comunitaria al aspirar a expandir o compartir valores que no solo considera como europeos sino como universales, la UE no ha querido o no ha sabido aplicar el principio de condicionalidad de la ayuda, tantas veces proclamado en los diferentes documentos surgidos de la propia Unión, limitándose a incentivar a los vecinos más aplicados en las reformas. Es evidente que este modo de actuar resta credibilidad a la acción exterior de la UE, además de resultar claramente ineficaz a los efectos que se persiguen, como ha quedado demostrado en las recientes turbulencias en el mundo árabe.

En efecto, todas las declaraciones a favor de los derechos humanos y libertades fundamentales, incluyendo a las minorías, la reforma política, el Estado de Derecho o la buena gobernanza, incorporadas al arsenal documental del proceso de Barcelona -desde la Declaración de 1995 a los acuerdos de asociación- pero también del relativo a la PEV -diversos documentos de la Comisión y los Planes de Acción- han sido sistemáticamente ignoradas por la UE cuando se han producido y mantenido en el tiempo situaciones claramente contradictorias con estas exigencias en numerosos países de la vecindad.

\footnotetext{
${ }^{73}$ Haukkala, Hiski: "The European Union as a regional normative hegemon: the case of European Neighbourhood Policy", Africa-Asia Studies, vol. 60, no 9 (2008), pp. 1601 y ss.

${ }^{74}$ Echeverría, Carlos: "Valoración de los éxitos y fracasos del Proceso de Barcelona desde la perspectiva de los países del Norte de África y Oriente Medio”, en Beneyto, José María (dir.) (2010): La apuesta por el Mediterráneo. Un reto para el siglo XXI, Madrid, Biblioteca Nueva, p. 77.
} 
La caracterización del llamado "poder blando de la UE", hubiera sido a todas luces compatible con una acción más decidida en situaciones claramente incompatibles con el discurso oficial incorporado en toda esta larga serie de documentos, declaraciones, tomas de posición, de carácter más soft pero también de acuerdos de asociación y planes de acción que presentan una connotación claramente más hard. La inaplicación del principio de condicionalidad ha sido clamorosa en todos los casos y tuvo que ser la primavera árabe la que puso de manifiesto con toda la crudeza, la flagrante situación escandalosamente deficitaria en materia de derechos humanos y libertades fundamentales presente en tales países, dejando a la UE en una posición claramente incómoda ante la que, por otra parte, reaccionó con una lentitud exasperante.

La pretensión de la UE de conseguir una periferia estable y pacificada que no exporte sus conflictos al interior de sus fronteras a cambio de una integración comercial y de ayudas financieras, pero sin una implicación a fondo en la resolución de los conflictos presentes y latentes en la región, ha demostrado ser una estrategia débil y en cualquier caso, insuficiente en cuanto a sus resultados. Los conflictos endémicos, en particular el de Oriente Medio, han terminado, al igual que ocurriera con el proceso de Barcelona, condicionando la PEV, en la medida en que han enrarecido enormemente el ambiente regional, han amenazado la estabilidad de la vecindad, retrasando el desarrollo económico y social, y, por supuesto, las reformas democráticas y el Estado de Derecho.

La fijación obsesiva de la UE por la cuestión de la seguridad y estabilidad en la región mediterránea $^{75}$, presente de forma evidente en la $\mathrm{PEV}$, ha demostrado sus profundas contradicciones, como se vio reflejado en las turbulencias acaecidas en el mundo árabe ${ }^{76}$. La UE, preocupada por ejercer en su vecindad más próxima, en particular en su flanco Sur, una influencia estabilizadora capaz de exportar seguridad y estabilidad a sus vecinos evitando importar su inestabilidad, no supo detectar anticipadamente tales turbulencias y lo que es mucho peor, no reaccionó con agilidad una vez producidas estas. Es evidente que el objetivo central de la PEV, que el profesor Khader definía como un "bulevar periférico" cuyas puertas de acceso al centro están controladas por este, no ha sido alcanzado, a pesar del bienintencionado propósito de lograr el bienestar de la periferia a través de una circulación fluida y sin trabas, que evite que las fronteras - controladas, pero no cerradas- se conviertan en un frente inestable ${ }^{77}$.

El énfasis en la dimensión bilateral y progresiva que implica la PEV ha tenido igualmente consecuencias diversas no siempre positivas, pues mientras la bilateralidad ha comportado una pérdida de la dimensión multilateral regional, la progresividad y la gradualidad, que han permitido avanzar más rápidamente a aquellos socios dispuestos a emprender el programa de reformas, ha tenido como consecuencia una diferenciada respuesta por parte de los vecinos. Así lo demuestran las actitudes de países como Marruecos, Túnez o Jordania, más proclives a las reformas, o como Argelia o incluso Egipto que lo han hecho más tardíamente.

\footnotetext{
${ }^{75}$ Brimmer, Esther: "Le voisinage de l'Union européenne: sphère de sécurité, ¿réseau de connections ou mariage de convenance?", Politique étrangère, no 1 (2008), pp. 25-37.

${ }^{76}$ Cfr. Guinea, Mercedes: "La Política Europea de Vecindad hacia el Mediterráneo (2003-2015): impotencia de la Unión Europea ante un entorno cada vez más hostil”, Revista UNISCI/UNISCI Journal, nº 39 (octubre 2015), pp. 261 y ss.

${ }^{77}$ Khader, Bichara "El círculo de amigos (ring of friends): la nueva Política Europea de Vecindad (PEV)", en Blanc Altemir, Antonio (ed.) (2008): Europa Oriental: en la encrucijada entre la Unión Europea y la Federación Rusa, Lleida, Centre de Cooperació Internacional de la Universitat de Lleida-Programa Jean Monnet (Comisión Europea), pp. 158-159.
} 


\section{La Unión por el Mediterráneo: un nuevo intento de revitalizar la cooperación}

\subsection{La fragilidad intrínseca de la UpM en sus primeros años}

A pesar de que tanto el Proceso de Barcelona como la PEV ya intentaban encauzar las relaciones de la UE con el flanco Sur del Mediterráneo, en 2007, el entonces candidato a la presidencia de República francesa, Nicolas Sarkozy, difundió una nueva propuesta, la Unión Mediterránea, la cual englobaría únicamente países con salida al Mare Nostrum y, por ende, se constituiría al margen de Bruselas. La iniciativa, por motivos obvios, lejos de entusiasmar, aglutinó serias reticencias que conllevaron varios rediseños, otorgándole de esa manera un halo de improvisación y de contradicción constante que presagiaba su descalabro.

Con el objetivo de evitar el fracaso del proyecto, el Consejo Europeo de marzo de 2008 promovió su futura puesta en marcha, siempre y cuando su metodología se fundamentase en la europeización. De modo que, en verano del mismo año, se celebró la Cumbre de Paris donde se adoptó la Declaración por la que se estableció la UpM como apéndice del Proceso de Barcelona y de la PEV, no constituyendo, por lo tanto, una verdadera alternativa a los cauces tradicionales.

Los iniciales 43 miembros -en la actualidad $42-{ }^{78}$ hubieron de afrontar una compleja confluencia de dinámicas unilaterales e intergubernamentales que caracterizaron los turbulentos primeros años de la UpM. De manera que, si políticamente la propuesta se lanzó en París, su puesta en marcha se perfiló con ocasión de la reunión ministerial de Marsella a finales de 2008 donde se acordaron las bases jurídicas para su pleno funcionamiento ${ }^{79}$. El Estatuto del Secretariado de la UE de marzo de $2010^{80}$, aprobado por los Altos Funcionarios y el Acuerdo de Sede entre el Reino de España y el Secretariado de la UpM, de mayo de $2010^{81}$ complementaron el entramado institucional ${ }^{82}$. En particular, en Marsella y entre otras cuestiones, se acordó conceder el aval específico a los seis proyectos adoptados en París ${ }^{83}$, así como el cambio de denominación ya que los ministros decidieron suprimir la referencia al Proceso de Barcelona y, por consiguiente, que la nueva iniciativa pasase a denominarse: Unión por el Mediterráneo ${ }^{84}$. Otra importante decisión radicó en la necesidad de reafirmar que, aunque la nueva entidad carecía de la dimensión securitaria y, por lo tanto, la Unión no trataría de reemplazar otras iniciativas para la resolución del conflicto árabe-israelí, el nuevo marco podría llegar a respaldar un eventual futuro éxito de las negociaciones ${ }^{85}$. Asimismo, se acometió el complejo asunto de la copresidencia, acordándose que Francia y Egipto la ostentarían en la

\footnotetext{
${ }^{78}$ A día de hoy, los miembros de la UpM son 42 países debido a la salida del Reino Unido de la UE, el 1 de enero de 2020. Sin embargo, ciertamente activos encontramos 41 a causa de la suspensión de Siria desde 1 de diciembre de 2011: los 27 Estados miembros, Albania, Argelia, Bosnia-Herzegovina, Egipto, Israel, Jordania, Líbano, Mauritania, Mónaco, Montenegro, Marruecos, Palestina, Túnez y Turquía. Libia ostenta el estatuto de observador. ${ }^{79}$ Barcelona Process: Union for the Mediterranean Ministerial Conference, Marseille 3-4 November 2008, en https://ufmsecretariat.org/wp-content/uploads/2015/10/Marseille-Declaration.pdf

80 Partenariat Euromed, Doc. Núm. $41 / 10$ anexo, Véase Badia, Anna Maria: "Modelos de cooperación institucionalizada entre los Estados: puntos de conexión con la Unión por el Mediterráneo (UpM)", en Huici, Laura (coord.) (2011): La Unión por el Mediterráneo: retos de la cooperación institucionalizada en la región, Barcelona, Marcial Pons, p. 34.

${ }^{81}$ BOE núm. 145, de 15 de junio de 2010.

${ }^{82}$ Véase Johansson-Nogués, Elisabeth: "The UfM's institutional structure: making inroads towards "coownership?", Mediterranean Politics, vol. 16, no 1 (2011), pp. 21-38.

${ }^{83}$ Hunt, Diana: "The UfM and development prospects in the Mediterranean: making a real difference?", Mediterranean Politics, vol. 16, nº 1 (2011), pp. 171-192.

${ }^{84}$ Reiterer, Michael: "From the French Mediterranean Union to the (European) Barcelona Process: the Union for the Mediterranean as a part of the European Neighbourhood Policy", European Foreign Affairs Review, vol. 14, $\mathrm{n}^{\circ} 3$ (2009), p. 327.

${ }^{85}$ Hollis, Rosemary: "The UfM and the Middle East "Peace Process": an unhappy symbiosis", Mediterranean Politics, vol. 16, no 1 (2011), p. 99-116.
} 
primera fase ${ }^{86}$. Sin embargo, no se abordó otro tema de vital importancia para la visibilidad del nuevo proyecto: el rol de la Asamblea Parlamentaria Euro-mediterránea y de la Asamblea Regional y Local Euro-mediterránea (ARLEM). Aquel importante encuentro permitió articular y sentar las bases de la arquitectura de la UpM en un contexto de constante amenaza de parálisis debido, entre otras cuestiones, a las desavenencias respecto al reparto de poder institucional.

\subsection{La inacabada consolidación de la UpM}

La única solución destinada a superar la parálisis política que dominó la primera etapa de la $\mathrm{UpM}^{87}$, se hallaba en la efectiva puesta en marcha de la Secretaría dado que, de esa manera, se otorgaría credibilidad a su cometido ${ }^{88}$. En 2011, cuatro años después de la presentación oficial en París y tras arduos esfuerzos, se celebró la primera reunión interinstitucional con el objeto de mostrar el firme apoyo a la $\mathrm{UpM}^{89}$. En ella se logró aprobar un primer proyecto consistente en la creación de una planta de desalinización de agua marina en Gaza ${ }^{90}$. A raíz de lo cual se decidió apostar por iniciativas en áreas sectoriales tales como la educación, el desarrollo empresarial, el agua o el transporte ${ }^{91}$. Se puede aseverar que la UpM no comenzó a cumplir sus funciones con plenitud hasta 2013 a través del lanzamiento de tres proyectos en el ámbito de la empresa, el medio ambiente y la logística ${ }^{92}$. Ahora bien, una vez se procedió a la ejecución de los proyectos, se experimentó un crecimiento exponencial de modo que en 2015 ya sumaban un total de 37 de los cuales 19 se hallaban en fase de implementación. Todo un logro considerando que el término "fracaso" sobrevolaba la iniciativa desde sus inicios.

Cabe puntualizar que la primavera árabe y sus consecuencias influyeron en la evolución y percepción de la UpM. En su seno y de forma inesperada, se atisbó la oportunidad de relanzar las relaciones euromediterráneas. A tenor de lo cual, la reunión informal a nivel

\footnotetext{
${ }^{86}$ Cuestión problemática debido a la propia arquitectura institucional de la UE, a las posturas de los Estados miembros y a las disparidades entre los países árabes respecto a qué significa este nuevo marco de cooperación.

${ }^{87}$ Florensa, Senen: "La Unión por el Mediterráneo: retos y ambiciones", Anuario IEMed del Mediterráneo 2010, Barcelona, IEMed, p. 61-62.

${ }^{88}$ En la actualidad, la estructura institucional se ciñe a la Copresidencia, aun ejercida por la UE y Jordania; los Altos Funcionarios, y la Secretaría. Esta última dirigida por el diplomático egipcio, Nasser Kamel, desde la primavera de 2018, con el apoyo de seis secretarios generales adjuntos que operan en las tradicionales divisiones sectoriales acorde a la rotación geográfica: energía y cambio climático (Italia), agua, medioambiente, y economía azul (España), asuntos civiles y sociales (Malta), desarrollo económico y empleo (Marruecos), transporte y desarrollo urbano (Turquía), educación e innovación (Túnez). En su empeño de adquirir visibilidad, la Secretaría se ha esforzado en articular una red integrada por socios institucionales -aparte de la UE, Fundación Anna Lindh, BUSINESSMED, Banco Europeo de Reconstrucción y Desarrollo, FAO, IEMed...-, por promotores de los proyectos -Agencia para la Cooperación Internacional y Desarrollo Local en el Mediterráneo, Banco Central de Jordania, Fundación Mujeres por África...- y por instituciones financieras internacionales -Banco Islámico de Desarrollo, el Banco Europeo de Inversiones...- que facilita la consecución y desarrollo de los proyectos, en https://ufmsecretariat.org

${ }^{89}$ European Neighbourhood Info Centre, Union for the Mediterranean: first inter-institutional meeting puts projects first, en

https://web.archive.org/web/20160304082447/http://enpi-info.eu/medportal/news/latest/31004/Union-for-theMediterranean:-first-inter-institutional-meeting-puts-projects-first

90 Gaza Desalination Project - The Largest Single Facility to be built in Gaza, en https://unispal.un.org/DPA/DPR/unispal.nsf/1ce874ab1832a53e852570bb006dfaf6/11b86e4431aa47c885257a6b 0053a8cc?OpenDocument

${ }^{91} \mathrm{Un}$ total de hasta trece proyectos fueron aprobados en un breve espacio de tiempo.

${ }^{92}$ Los proyectos fueron los siguientes: Mujeres jóvenes creadoras de empleo (comprendería tres fases de desarrollo implicando cada vez más partners desde los cuatro iniciales -Marruecos, Jordania, Territorios Palestinos y Españaa un total de once- con el objetivo de apoyar a emprendedoras), Gobernabilidad y Financiamiento del Agua en el área mediterránea (con la finalidad de diagnosticar las dificultades de la gestión para atraer inversión privada de modo que se implementaría entre 2013-2015, en un principio con la participación de seis países), y por último, LogismedTA (que se ejecutaría en diez países socios y en cinco plataformas de logística a fin de mejorar actividad de los centros).
} 
ministerial en el Palacio de Pedralbes -Barcelona- el 13 y 14 de abril de 2015 fue calificada como un éxito por Mogherini, la entonces Alta Representante, dado que, tras siete años de espera, se celebró el esperado encuentro ${ }^{93}$. Durante aquellas dos jornadas los asistentes trataron asuntos dispares entre los que destacaron por su acuciante actualidad, la migración y el terrorismo ${ }^{94}$. No obstante, la rapidez de los acontecimientos y la escueta acción de Bruselas impidieron progresos creíbles.

Sin lugar a dudas, la coyuntura de la zona demandaba un análisis profundo que trajo como consecuencia la enésima revisión de la PEV a fin de abordar la necesidad más acuciante, la estabilización. Al referirse a aquélla, no se podía circunscribir únicamente a la seguridad desde el paradigma tradicional, sino que había de enfocarse en las diversas fuentes de inestabilidad: desigualdad, débil desarrollo económico y social, pobreza y corrupción, entre otras, con el propósito de dinamizar la cooperación. En aquel entonces se perfilaba el papel transcendental que podía desempeñar la UpM en la dimensión regional en vista de que había demostrado ser un importante foro de debate político y económico, y de que brindaba un marco apropiado para la cooperación sobre temas de interés común y proyectos operativos en la región, en atención a lo cual la UE daría prioridad a la UpM en sus esfuerzos de cooperación regional. Al aval europeo, le siguió el valioso respaldo internacional, a iniciativa de Jordania, gracias al otorgamiento de la condición de observador en noviembre por parte de la Asamblea General de Naciones Unidas a finales de $2015^{95}$. Un paso más hacia la visibilidad que vino a sumar el reconocimiento de la Fundación Española de Fomento Europeo por su labor respecto a los valores universales y los derechos humanos en la región mediterránea ${ }^{96}$.

En el año 2015, las expectativas comenzaron a cristalizarse de manera tangible y la UpM se convirtió en un ecosistema único o plataforma de enfoque colaborativo que a partir de la descentralización contribuía eficientemente a la cooperación regional beneficiando la red de más de 10.000 stakeholders: instituciones, universidades, investigadores, representantes empresariales, parlamentarios, autoridades locales, sector privado, ONGs y sociedad civil. Los tres axis de trabajo: empleabilidad juvenil y crecimiento inclusivo, empoderamiento femenino y desarrollo sostenible acogían 41 proyectos promocionados desde distintos ámbitos: organizaciones internacionales, instituciones financieras, administraciones nacionales, sector privado, instituciones educativas y de investigación y, sobre todo, por la sociedad civil ${ }^{97}$. Otro rasgo de la plena implementación se atisbó en el hecho de que, desde 2013, siete conferencias

\footnotetext{
${ }^{93}$ Remarks by the High Representative and Vice-president Federica Mogherini at the Press conference of the Informal Ministerial meeting with Southern ENP partners on the future of European Neighbourhood Policy, Barcelona, 13.04.2015, en http://www.eeas.europa.eu/statements-eeas/2015/150413_02_en.htm

${ }^{94}$ La Alta Representante sugirió que este tipo de reuniones se celebrase con carácter anual para intercambiar opiniones. En lo concerniente a los socios, las propuestas giraron en torno a temas tan divergentes como los siguientes: Madrid expuso su planteamiento de crear una Corte Criminal Internacional especializada en terrorismo. Marruecos, Túnez y Argelia introdujeron la ineludible profundización de las relaciones comerciales, mientras que Jordania se centró en la crisis humanitaria a causa del entonces ya persistente conflicto en Siria (en aquel momento, Amman acogía a más de un millón y medio de refugiados). Por su parte Egipto, remarcó la necesidad de afrontar las contiendas no solamente en Trípoli o Damasco, sino también en Saná -Yemen-. Israel, sin embargo, subrayó la necesidad de emprender un mayor intercambio en el ámbito de la alta tecnología., mientras que Palestina se ciñó a atraer la atención en su conflicto con Tel-Aviv.

${ }^{95}$ Asamblea General de Naciones Unidas, A/RES/70/124 Otorgamiento de la condición de observador en la Asamblea General a la Unión por el Mediterráneo, Septuagésimo periodo de sesiones, 14.12.2015.

96 , en https://www.lavanguardia.com/politica/20160311/40366732577/fundacion-de-fomento-europeo-analizaen-barcelona-los-retos-de-europa.html

${ }^{97}$ Union for the Mediterranean - Activity Report 2015, p. 7: De los 45 proyectos, el 20\% se enfocaban en agua y medioambiente, el $16 \%$ en educación terciaria e investigación, el $20 \%$ en asuntos sociales y cívicos, el $20 \%$ en desarrollo empresarial, el $8 \%$ en energía y acción climática y el 16\% en transporte y desarrollo urbanno.en https://ufmsecretariat.org/wp-content/uploads/2016/06/UfM-Activity-Report_FINAL_WEB.pdf
} 
ministeriales y más de quince reuniones de alto nivel se habían celebrado ${ }^{98}$. Sin embargo, la financiación aun constituía un obstáculo teniendo en cuenta que la asignación presupuestaria propuesta por la Comisión para el período 2014-2020 dedicó 16.100 millones de euros al IEVA, cifra que no permitía alcanzar importantes metas ${ }^{99}$.

A pesar del optimismo que rodeaba la UpM debido al incremento de actividad de la Secretaría ${ }^{100}$, en enero de 2017, los ministros de Asuntos Exteriores de los socios asumieron la metodología tradicional europea para evitar la fatiga: el relanzamiento de la iniciativa mediante el "Roadmap for Action: the UfM: an action-driven organisation with a common ambition"101 que inició una tercera fase ${ }^{102}$. El Roadmap se componía de cuatro áreas de acción que propiciarían el reforzamiento de los objetivos de la organización. Conviene resaltar que las áreas no se circunscribirían a una lista taxativa, sino que podrían ser objeto de revisión o ajuste de forma regular acorde a las necesidades futuras:

En primer lugar, intensificar el diálogo político entre los Estados miembros de modo que cuanto más integral, mayor efectividad se lograría en el momento de implementar las actividades. Pese a que la dimensión política quedó fuera de este ámbito desde un principio de la actuación de la UpM, no se podía ignorar que aquella carencia viciaba toda iniciativa. En vista de la necesidad de la estabilidad y, por ende, de abordar los factores que provocaban su distorsión, los ministros decidieron incorporar dicha cuestión al debate. Ahora bien, otro aspecto igualmente imprescindible radicaba en la coordinación de toda la estructura institucional desde las asambleas parlamentarias a las reuniones ministeriales de carácter sectorial, de ahí la urgencia de amparar las actuaciones mediante una agenda común que facilitase la sinergia con la $\mathrm{PEV}^{103}$.

En segundo lugar, se garantizaría la contribución de las actividades de la UpM a la estabilidad regional y al desarrollo humano. Los Ministros pusieron de relieve cuatro retos en cuyos ámbitos se concentrarían las acciones específicas: el diálogo intercultural e interreligioso en base al legado común con el fin de luchar contra el radicalismo o el racismo; la movilidad, migración y desarrollo, a dicha triada le urgía un enfoque global y equilibrado acorde a los instrumentos internacionales existentes; y la prevención del extremismo y terrorismo, dado el alto nivel de amenaza por lo que se imponía la necesidad de actualizar el Código de Conducta Antiterrorista, adoptado en 2005, en línea con la Estrategia de las NNUU contra el Terrorismo. Respecto al desarrollo, aproximadamente un $60 \%$ de la población de los países mediterráneos se situaba en aquel momento, por debajo del umbral de los 30 años, cifra que se incrementaría considerablemente en 2020, de manera que las reducidas cifras de jóvenes que entraban en el mercado laboral cada año en la región, incrementaban hasta unos niveles insostenibles el

\footnotetext{
${ }^{98}$ Además, continuaba la cooperación con otros stakeholders: Asamblea Parlamentaria de la UpM, Parlamento Europeo -celebrando su Informe de Actividad en su seno-, Asamblea Parlamentaria del Mediterráneo, ARLEM, Fundación Anna Lindh, Comité de las Regiones, Consejo Económico y Social Europeo, UNESCO -se firmó un Memorándum de Entendimiento por el que se estableció la colaboración entre ambas instituciones en la promoción de proyectos destinados, en concreto, a la juventud mediterránea, OSCE, Liga Árabe, Consejo de Estados del Mar Báltico, Grupo Visagrad, Unión del Magreb Árabe, entre otros.

${ }^{99}$ Un presupuesto para Europa 2020. Parte II: Fichas sobre Políticas, COM(2011)500 final Parte II, Bruselas, 29.06.2011, p. 50.

100 Union for the Mediterranean - Activity Report 2016, en https://ufmsecretariat.org/wp-content/uploads/2017/05/2016-Annual-Report_-UfM.pdf

${ }^{101}$ UfM roadmap for action. The Union for the Mediterranean. An action-driven organization with a common ambition adopted by the UfM Ministers of Foreign Affairs, on 23 January 2017 in Barcelona, en https://ufmsecretariat.org/wp-content/uploads/2017/10/UfM-Roadmap-for-action-2017.pdf

102 Albinyana, Roger: "The Union for the Mediterranean in 2017: stocking and consolidation", IEMed Mediterranean Yearbook 2017, Barcelona, IEMed, pp. 217-221.

${ }^{103}$ UfM roadmap for action..., op. cit. pp. 10-11.
} 
desempleo. Con el objeto de atajar semejante panorama se establecería la Iniciativa Med4Jobs dedicada a la promoción de la creación de empleos.

En tercer lugar, la escasa integración económica en la región euro-mediterránea persistía tras veinte años de la instauración del Proceso de Barcelona. Pese a este factor todos los socios eran conscientes del gran potencial que una mayor integración podría acarrear en un futuro. Por consiguiente, no se debía abandonar la senda de los Acuerdos de Asociación y de otros instrumentos de libre comercio ni tampoco las incipientes negociaciones con algunos PSM de nuevos acuerdos con el fin de profundizar sus relaciones con la UE, al mismo tiempo que se debía concentrar mayor esfuerzo para atraer IED o adoptar medidas que facilitasen el acceso al mercado del sector privado. En este sentido tampoco se podía obviar que el vacío o gap de la conectividad infraestructural agravaba aun más, si cabe, la coyuntura e impedía un efecto multiplicador de los beneficios, de modo que la Secretaría proseguiría impulsando proyectos en el sector de transporte y energético, en particular de aquellos que favoreciesen el desarrollo sostenible en coherencia con los Objetivos de Desarrollo Sostenible (ODS) ${ }^{104}$.

En cuarto lugar, uno de los aspectos más complejos y de más difícil solución de la UpM, ha sido su capacidad real de acción. Los acontecimientos y los conflictos recurrentes en la región evidenciaban que la multiplicidad de los marcos no solo no facilitaba una respuesta útil, sino que, todo lo contrario, enmarañaba cualquier acercamiento. Por tanto, si se pretendía que, en la nueva fase, la UpM no volviese a incurrir en los mismos errores, se había de acometer acciones destinadas a intensificar su articulación con la PEV, en particular tras el "refrendo" que había supuesto la última revisión de dicha política. Desde una perspectiva operacional se evitarían duplicidades; se afianzaría el acceso a fondos europeos; se consolidaría la coordinación entre los distintos instrumentos financieros y se reforzaría la dimensión regional del IEVA. El presupuesto habría de acompañar el incremento de actividad considerando que hasta 2017, se había alcanzado la cifra de 47 proyectos financiados -de los cuales 25 se habían completado- con un coste superior a los 5.000 millones de euros, en relación con lo cual los gastos corrientes de la UpM rondaban los 8,4 millones de euros a cubrir en un $50 \%$ por la Comisión y un $50 \%$ por los Estados miembros. Por último, se resaltó el hecho de que más de dos tercios de los proyectos se financiaban a través de subvenciones que permitían un uso eficiente de los fondos de modo que se continuaría garantizando dicho mecanismo. Respecto a la financiación de los proyectos de infraestructuras, la Secretaría se focalizaría en la coordinación de las sinergias entre los diferentes instrumentos y promotores. Finalmente, en este cuarto ámbito de trabajo y con el propósito de expandir el campo de influencia de la UpM, se formularía un enfoque específico con la finalidad de profundizar las interacciones entre los distintos stakeholders -civiles, gubernamentales y privados- puesto que habían resultado altamente eficientes en los inicios de aquélla ${ }^{105}$.

En quinto y último lugar, a fin de examinar y ajustar las iniciativas se celebraría cada año en noviembre en Barcelona el Foro Regional. Este marco único ofrecía la oportunidad de reunir a ministros de Asuntos Exteriores de los miembros, stakeholders y otras instituciones para avanzar en la implementación del Plan de Acción ${ }^{106}$.

En definitiva, la UpM recibió un impulso considerable cuando ya los analistas recalcaban su irrelevancia, debido al agotamiento de ideas y de interés de la UE que se hallaba inmersa en una crisis de gran envergadura, como era el Brexit ${ }^{107}$.

\footnotetext{
${ }^{104}$ Ibid., pp. 17-19.

${ }^{105}$ Ibid., pp. 20-24.

${ }^{106}$ Ibid., p. 25.

107 Pierini, Maurizio: “The crisis of the European project and its consequences for the Euro-Mediterranean agenda”, IEMed Mediterranean Yearbook 2018, Barcelona, IEMed, pp. 114-118.
} 


\section{La Nueva Agenda para el Mediterráneo: ¿nueva, ambiciosa e innovadora?}

La UE ha mostrado en sucesivas ocasiones voluntarismo e imaginación en la articulación de sus relaciones con el Mediterráneo meridional, pero todavía no ha encontrado el modelo a aplicar. Las grandes expectativas generadas por la AEM, la PEV o la UpM han tenido resultados modestos en la práctica, aunque mejores en las dos primeras que en la tercera, que continúa sumida en una notable falta de visibilidad. En cualquier caso, no han desplegado la energía suficiente para generar un verdadero cambio capaz, no solo de revertir una situación endémica de asimetría y fractura entre las dos riberas, sino tan solo de lograr una mejora apreciable ${ }^{108}$.

Sin lugar a dudas, el afán de la UE de diseñar propuestas es encomiable puesto que ha asumido desde hace tiempo que comparte con los PSM desafíos comunes a los cuales les urge una respuesta también común. De ahí que no haya causado sorpresa alguna que, frente a aniversarios tan significativos, una vez más se intente vehicular la relación entre ambas orillas introduciendo una asociación renovada con los vecinos meridionales a través de "Una nueva Agenda para el Mediterráneo" 109 . Un documento de soft law que, pese a su imposibilidad de producir efectos jurídicos, crea obligaciones tanto para las instituciones como para los Estados miembros. Por ello, el Consejo Europeo de diciembre de 2020 ya avanzó que la UE estaba determinada a relanzar, reforzar y desarrollar el marco del PEM guiada por las directrices de la Agenda Estratégica 2019-2024 de la Comisión, los principios de la PEV y la necesidad de hacer un uso efectivo de todos los instrumentos. De igual modo añadió que la futura Comunicación había de fundamentarse en un diálogo político intensificado sin desperdiciar la ocasión para reforzar el papel de la sociedad civil ${ }^{110}$.

El 9 de febrero de 2021 se presentó el último intento de la UE de cooperación con la finalidad de abrir una nueva etapa. Sin embargo, cabe la posibilidad de que nos hallemos ante el día de la marmota a causa de una considerable falta de imaginación o de un exceso de reiteración. Por tanto, a continuación, se analizará el contenido del documento con el objeto de determinar si, en efecto, dicho instrumento incorpora nuevas áreas e involucra a los PSM canalizando nuevas formas de cooperación o si, por el contrario, adolece de novedad alguna marginando al vecindario Sur.

A partir de un análisis de los retos de gobernanza, socioeconómicos, climáticos, medioambientales y de seguridad que asolan la región y que se han visto acentuados por la pandemia de COVID-19, se afirma que la falta de una acción conjunta tanto de la UE como de los socios meridionales limita considerablemente las soluciones efectivas. Indudablemente existe una evidente relación de interdependencia que determina que cualquier factor de crisis ya sea política, social o económica de los países vecinos, se refleja inmediatamente en la UE. Partiendo de esta constatación, la nueva Agenda para el Mediterráneo busca a través del diálogo y de los valores comunes, progresar en asuntos socioeconómicos, así como políticos de manera que esta etapa de recuperación se adapte igualmente a instrumentos internacionales de gran alcance, en particular la Agenda 2030 para el Desarrollo Sostenible y el Acuerdo de París.

Resulta interesante subrayar que la Comunicación delimita el objetivo de construir "sociedades más equitativas, prósperas e integradoras, en beneficio de las personas, especialmente de los jóvenes" 111 para lo cual propone las siguientes orientaciones prioritarias:

\footnotetext{
${ }^{108}$ Razón por la que algunos reclamaban desde hace tiempo un nuevo impulso para el PEM y en general para las relaciones euro-mediterráneas. Cfr. Blanc Altemir, Antonio: "El proceso euromediterráneo: una década de luces y sombras", Anuario de Derecho Internacional, vol. XXI (2005), pp. 185-225.

109 Asociación renovada con los países vecinos meridionales. Una nueva Agenda para el Mediterráneo, JOIN(2021)2 final, Bruselas, 09.02.2021.

${ }^{110}$ Conclusiones del Consejo Europeo, EUCO 22/20, Bruselas, 10 y 11 de diciembre de 2020.

${ }^{111}$ Asociación renovada con..., op. cit., p. 2.
} 
de carácter económico: un Plan Económico y de Inversión; de carácter ambiental: la lucha contra el cambio climático, reducir las emisiones nocivas, utilizar los recursos de manera sostenible y acelerar la transición ecológica; de carácter político: un compromiso renovado con el Estado de Derecho, los derechos humanos y libertades fundamentales, la igualdad, la democracia y el buen gobierno; de carácter securitario: afrontar conjuntamente los desafíos que representan los desplazamientos forzosos y la migración irregular y aprovechar las ventajas de la migración legal de manera eficiente y efectiva, por medio de colaboraciones exhaustivas, adaptadas y de interés mutuo, protegiendo los derechos de los migrantes y de los refugiados en consonancia con el Nuevo Pacto Europeo sobre Migración y Asilo; y finalmente, de carácter geopolítico: un compromiso renovado con la unidad y la solidaridad entre los Estados miembros de la UE, así como un compromiso mutuo y compartido que implique acciones conjuntas con los países asociados de la vecindad meridional.

\subsection{Las acciones de la Nueva Agenda para el Mediterráneo}

Tomando en consideración las orientaciones preestablecidas, se proponen una serie de acciones en áreas claves que lejos de ser novedosas, dado que reiteran el contenido de los tres cestos del Proceso de Barcelona así como los principios de la PEV, vienen a evidenciar el escaso éxito de la UE hasta el momento presente. Aunque en esta ocasión no se ha de desdeñar el hecho de que por cada acción se proponen y matizan las iniciativas que se financiarán de acuerdo con el futuro instrumento.

\subsubsection{El desarrollo humano, el buen gobierno y el Estado de Derecho}

La primera acción concatena el desarrollo humano con el buen gobierno y el Estado de Derecho dando lugar a una visible falta de concreción al vincular la mejora de la calidad de vida a la defensa de los derechos y libertades mediante un lenguaje naíf donde rigen verbos programáticos: apoyar, promover, proporcionar, desarrollar o participar en acciones. La falta de concreción trata de ser solucionada haciendo uso del Instrumento de Vecindad, Desarrollo y Cooperación Internacional que proporcionará una asistencia financiera adicional a los países que demuestren una indudable ambición de ejecutar reformas.

Respecto al desarrollo humano, elemento clave de la Agenda, se persigue mejorar la calidad de vida de las personas, aunque no solo en lo referente a la economía sino también en lo referente a los derechos y libertades políticas y sociales. La salud se articula como un tema muy relevante puesto que, a raíz de las circunstancias sanitarias actuales, hemos aprendido que aquélla resulta de vital importancia a la hora de gozar de una vida digna. Sin duda alguna, los desafíos de seguridad sanitaria y de los sistemas de salud han provocado pérdidas económicas tanto a corto como a largo plazo, por tanto, urge alentar acciones destinadas a reforzar el sistema sanitario y a sus profesionales. En especial, se pondrá el énfasis en desplegar el mecanismo COVAX ya que las vacunas son un bien común. Ahora bien, la UE entiende que no cabe despilfarro de los recursos de manera que exigirá que los países receptores diseñen una estrategia coherente que sea implementada con eficiencia.

Observando que la falta de expectativas de la juventud de la orilla Sur frena su condición de agente de cambio, las acciones planteadas conjugan la coordinación entre ámbitos estratégicos apostando principalmente por las colaboraciones con organizaciones juveniles. Asimismo, se facilitará el acceso de los PSM a los programas -Erasmus+, Europa Creativa, entre otros- y redes de la UE. Todas las actuaciones deben comprender las prioridades de la Agenda 2030 de las NNUU.

Por último, se menciona la promoción del buen gobierno y el Estado de Derecho, sin traer a colación, en ningún momento, la intención de hacer uso de las cláusulas de condicionalidad que contienen los Acuerdos de Asociación. De manera que las intenciones se 
ciñen a la búsqueda de compromisos con el fin de llevar a cabo reformas estructurales en consonancia con el Plan de Acción de la UE para los Derechos Humanos y la Democracia 2020$2024^{112}$. Ahora bien, en esta ocasión se incluirán ámbitos novedosos: la digitalización, la gobernanza de internet y el funcionamiento de las redes sociales a los cuales se les ha de prestar especial atención. En línea con lo cual se afirma que la democracia no se ciñe al cumplimiento de la ley, sino que también incumbe el fraude y la corrupción entre otros delitos financieros por lo que se buscará una mayor cooperación con la Oficina Europea de Lucha contra el Fraude. Otros sectores como la sociedad civil, la comunidad empresarial, las mujeres o las personas discapacitadas, serán objeto de preocupación en las iniciativas debido a la necesidad de integrar a toda la colectividad social.

\subsubsection{EI fortalecimiento de la resiliencia, la creación de prosperidad y el aprovechamiento de la transición digital}

La segunda acción coincide con el cesto de cooperación económica y financiera pero adaptado a las exigencias actuales de la pandemia la cual ha puesto de manifiesto la necesidad de unas economías resilientes, sostenibles, conectadas e integradoras. En virtud de cada adjetivo el documento sienta las bases o directrices que han de dirigir el aspecto económico de la cooperación. De manera que para que la economía sea resiliente, se pautan las acciones que se han de poner en marcha y que van desde crear amortiguadores contra futuras crisis, a la asistencia macrofinanciera -principalmente a través de apoyo presupuestario-, pasando por la mejora del clima empresarial con el fin de dotar de mayor confianza a los operadores e inversores del sector privado local e internacional.

Una economía sostenible implica una diversificación, la cual requiere el crecimiento de las economías verdes y digitales sin obviar el potencial de la economía azul siempre acorde a los objetivos delimitados por los diálogos sectoriales de la UpM. Una de las consecuencias inmediatas de la pandemia ha sido la ineludible reestructuración de las cadenas de valor mundiales, factor que intrínsecamente crea nuevas oportunidades de integración entre la UE y los vecinos del Sur. No obstante, la profundización de la integración no se ha de limitar a las grandes corporaciones, sino que igualmente ha de comprender las pymes y a empresas emergentes.

Una economía conectada entraña, aparte de una transformación digital, la oportunidad de liberar el potencial de la región. En realidad, se trata de crear mejores conexiones digitales en el Mediterráneo con el propósito de contribuir a una mayor integración económica. Este último aspecto enlaza con la prioridad de modernizar las relaciones comerciales en base a la actual red de Acuerdos de Asociación, en particular de impulsar las negociaciones en curso con Marruecos y Túnez con el objeto de concluir acuerdos sobre una zona de libre comercio de alcance amplio y profundo, así como de abrir un diálogo exploratorio con el resto de países sobre este asunto. No obstante, las oportunidades no se han de limitar a la mera dimensión birregional, sino que se han de explorar sinergias continentales -África- o subregionales - África Subsahariana- que faciliten la aparición de cadenas de valor y el incremento de las inversiones.

Una economía integradora procura fomentar la igualdad de oportunidades a la par que prioriza el diálogo social, la protección social y la inclusión. La UpM, debería canalizar el diálogo sectorial en materia de empleo y trabajo, así como implementar estrategias de recuperación aprovechando sus recursos. El planteamiento focaliza los resultados en los jóvenes, en la participación de la mujer en el mercado laboral, pero sobre todo en la tarea de formalizar la economía informal dado que, al lograrse el último objetivo, sus beneficios repercutirían en la ciudadanía y en las finanzas públicas.

${ }^{112}$ Plan de Acción de la UE para los Derechos Humanos y la Democracia 2020-2024 JOIN(2020)5. 


\subsubsection{La paz y la seguridad}

La tercera acción aborda los desafíos en materia de paz y seguridad en el Mediterráneo. En este ámbito la UE tiene bien aprendida la lección dado que, tal como se ha sostenido en el presente trabajo, la conflictividad latente y prolongada en la región ha constituido y constituye un importante obstáculo para el éxito de cualquier propuesta, por tanto, si no se acometen sus causas y no se apuesta por la prevención, resolución y cooperación en materia de seguridad, el fracaso de la Nueva Agenda será inevitable. La UE recalca que además de ser el principal proveedor de ayuda humanitaria y asistencia al desarrollo es igualmente un proveedor de seguridad cuya credibilidad se cimienta en su respeto al Derecho internacional. Esa confianza permite que la UE se encuentre en una posición única para llevar a cabo labores de diplomacia activa y que, asimismo, numerosos socios del Sur demanden una mayor intervención y esfuerzos en lo concerniente a la resolución de conflictos duraderos en la región. Ahora bien, se ha de puntualizar que la experiencia ha demostrado que solo cuando la UE habla y actúa al unísono puede ser ciertamente efectiva, de lo cual se infiere que la participación de todos los Estados miembros es clave.

Respecto al proceso de paz de Oriente Próximo, se tratará de alentar y aprovechar el reciente establecimiento de relaciones diplomáticas entre Israel y algunos países árabes, por ejemplo, Marruecos, con miras a mejorar las perspectivas de alcanzar una solución negociada. Sin embargo, otras coyunturas - Siria, Líbano, Libia, Sáhara Occidental o la región del Sahelprecisan especial atención ya sea para proponer soluciones o intensificar el apoyo siempre contando con las NNUU además de actores u organizaciones regionales, en particular la Liga de Estados Árabes, la Unión Africana y otras agrupaciones subregionales.

La herramienta principal para salvaguardar la estabilidad y seguridad en todos los frentes -paz, comercio, Estado de Derecho o juventud- pasa por el diálogo pacífico basado en el derecho internacional, así como en el apoyo al sistema multilateral, en particular de las NNUU.

Aparte de los conflictos enquistados existen otras graves amenazas para la seguridad que se han de atajar conjuntamente: terrorismo, radicalización, amenazas híbridas, ciberdelincuencia, delincuencia organizada o cambio climático, puesto que tienen lugar y producen efectos en ambas orillas del Mediterráneo. De un lado, la Comunicación destaca el terrorismo comprendiendo el fenómeno de los combatientes terroristas extranjeros y su creciente financiación, por lo que, a partir de los canales y la cooperación existente, se ha de continuar trabajando en la profundización e intensificación en varios frentes, en particular el ámbito policial, el diálogo intercultural e interreligioso y la asistencia técnica.

De otro lado, otra amenaza de creciente interés no consiste en la digitalización ${ }^{113}$ per se, sino en sus vulnerabilidades que puede acarrear consecuencias en sectores ciertamente heterogéneos desde el energético, bancario o sanitario, de ahí que resulte imprescindible desarrollar la ciber resiliencia mediante el pleno uso de los marcos internacionales vigentes Convenio de Budapest- de modo que se luche contra la desinformación, se compartan las buenas prácticas, se formen a expertos en ciberseguridad y se exploren las posibilidades que ofrecen herramientas innovadoras para las fuerzas del orden, con pleno respeto de los derechos humanos y las libertades civiles. Teniendo en cuenta que el hilo conductor de la propuesta reside en hacer uso de todas las herramientas disponibles, se propone que se utilicen aquellas que recoge la Estrategia de la UE para una Unión de la Seguridad ${ }^{114}$ con el objetivo de reforzar la capacidad de las autoridades policiales, judiciales y civiles, y, por añadidura, de la cooperación

\footnotetext{
${ }^{113}$ Sidlo, Katarzyna : "Digital transformation in the Southern Neighbourhood" Euromed Survey 2020 Qualitive Result, en https:/www.euromesco.net/wp-content/uploads/2021/06/ES11_Qualitative-3-Sidlo-102-110.pdf ${ }^{114}$ Estrategia de la UE para una Unión de la Seguridad COM(2020)605 final.
} 
entre ellas. La insistencia en el aspecto de cooperación contempla recurrir a las agencias de la UE -Europol, Cepol, Frontex, Observatorio Europeo de las Drogas y las Toxicomanías, Eurojust- para que, mediante la negociación de acuerdos de cooperación, se fortalezca la relación.

La cooperación judicial no se circunscribe únicamente a los medios o el respeto de los derechos humanos, sino que igualmente se ha de mejorar la ejecución de los convenios y abordar la sustracción transfronteriza de menores, la protección del menor y las obligaciones de manutención en virtud de la cual se prioriza la adhesión y la correcta aplicación de los Convenios de La Haya sobre Derecho Internacional Privado por parte de los PSM. Finalmente, la UE propone seguir desarrollando su asociación en el área de seguridad marítima y vigilancia costera. En su pretensión de garantizar resultados concretos aboga por la adaptabilidad a las respectivas necesidades de modo que el proyecto goce de apoyo político de alto nivel inclusive de la OTAN.

\subsubsection{La migración y la movilidad}

La cuarta acción, lejos de resultar innovadora se ocupa de un fenómeno que siempre se ha tratado desde una perspectiva securitaria: la migración y la movilidad. Una vez más se insiste en su carácter global dado que ningún país puede gestionarlas de forma efectiva por su cuenta. El Nuevo Pacto sobre Migración y Asilo de la UE sienta las bases para una gestión a largo plazo que pretende atajar la problemática centrándose en asociaciones exhaustivas, adaptadas, equilibradas y de interés mutuo. No obstante, el nuevo instrumento en realidad persiste en la gobernanza de la migración y el asilo que se concreta en el imperativo de regular el fenómeno de manera que se eviten desplazamientos peligrosos e irregulares mientras se focalizan los esfuerzos en la lucha contra el tráfico ilícito. Las asociaciones abarcan los diferentes aspectos del asunto y, por supuesto, se toman en consideración los intereses de la UE y de los países asociados. No se ha de obviar que cada país se enfrenta a situaciones específicas y presenta sus propias oportunidades, por lo que un planteamiento univoco no aporta una solución adecuada, sino que ahonda en un enfoque equivocado.

Además de poner el énfasis en combatir las redes delictivas, se sigue apostando por la cooperación en materia de retorno, readmisión y reintegración sostenible, subrayándose que las asociaciones se fundamentan en dichas acciones y con el objetivo de desplegar su efectividad, se movilizarán las políticas, herramientas e instrumentos pertinentes de la UE. Dada la importancia de los retornos voluntarios, la Comisión Europea adoptará una estrategia en materia de retorno voluntario y reintegración que defina nuevos enfoques.

Por otro lado, la cuestión migratoria, con su dimensión poliédrica, no se ha de acometer exclusivamente desde un paradigma Norte-Sur, pues igualmente ha de comprender la cooperación regional y multilateral integrando, asimismo, la cooperación triangular y Sur-Sur dado que algunos asociados son al mismo tiempo origen, tránsito y destino de aquélla. A escala regional, se promoverá la cooperación en el marco del Plan de Acción Conjunto de la Veleta y los Procesos de Jartum y de Rabat, de manera que se tenga en cuenta el fenómeno en su totalidad. En este contexto, se valora la cooperación trilateral con las NNUU y otros actores regionales como la Unión Africana puesto que aquélla ha sido fructífera respecto a Libia. Por último, la Comisión y el Alto Representante proponen utilizar todas las herramientas de que dispone la UE, incluidas las agencias europeas y el IVDCI -cuyo 10\% se destinará a medidas relativas a la migración-, así como instrumentos internos a fin de que la asistencia logre resultados tangibles. 


\subsubsection{La transición ecológica: resiliencia al cambio climático, energía y medio ambiente}

La quinta acción emprende la difícil tarea de la transición ecológica que engloba la resiliencia al cambio climático, la energía y el medio ambiente. La razón por la cual se trae a colación este reto radica en que la vecindad meridional es uno de los puntos críticos del planeta respecto al deterioro medioambiental ${ }^{115}$. Pese a una coyuntura tan negativa, la región mediterránea alberga algunos de los mejores recursos solares y eólicos del mundo, por lo que se han de explorar y explotar las oportunidades respecto a la energía limpia, especialmente a la producción de hidrógeno. Eso si, toda acción que se acuerde y se lleve a cabo debe atender a los principios del Acuerdo de París y del Pacto Verde puesto que ambos vertebran las prioridades estratégicas.

En lo referente al crecimiento verde y la acción climática, la UE pretende, en consonancia con los planes nacionales, impulsar medidas de acción coherentes, alcanzables y cuantificables. Estos adjetivos significan que se ha de prestar atención a la gobernanza climática y medioambiental que a su vez se vincula a las finanzas públicas y a la fiscalidad, a la fijación de precios del carbono, al aumento de la capacidad administrativa y a la asistencia técnica, así como a la sensibilización y educación. Todos los aspectos mencionados no son fáciles de encarar por los PSM ya que presentan remarcables déficits en la materia por lo cual se pretende una mayor implicación en el diálogo político coordinado y reforzado por parte de las autoridades públicas, del sector privado y de la sociedad civil. Los objetivos pueden desdibujarse si las instituciones financieras internacionales y el sector privado no se involucran respaldando el crecimiento sostenible. En particular, la voluntad de avanzar se asocia igualmente a la Plataforma Internacional de Finanzas Sostenibles que puede llegar a convertirse en un polo de intercambio de las mejores prácticas donde se coordinen esfuerzos en inversiones sostenibles desde el punto de vista medioambiental -taxonomías ecológicas- se amplíe la información sobre el medio ambiente y el clima, así como de las normas y etiquetas para lo productos financieros ecológicos.

En relación con la transición y seguridad energética, la cooperación se ha de adaptar a los diversos fondos de dotación y necesidades de los asociados de modo que los objetivos prioritarios se concentran en: desplegar las energías renovables y producir hidrógeno limpio con la finalidad de contribuir a la aspiración de instalar al menos 40 gigavatios de capacidad de electrolizadores en la vecindad de la UE para 2030; en aumentar la interconexión de los sistemas eléctricos o en formular políticas para hacer frente a las emisiones fugitivas de metano generadas por la producción, el transporte y el uso de combustibles fósiles conforme al marco establecido en la estrategia de la UE relativa al metano.

En cuanto a la gestión eficiente de los recursos, esta supone luchar contra la contaminación a la par que proteger la biodiversidad tanto marina como terrestre, animal y vegetal. Las medidas de apoyo incorporan actividades en varios ámbitos que van desde la sensibilización y educación, la creación de instalaciones modernas que garanticen el reciclado o la reforma de los marcos legislativos, fiscales e institucionales entre otras. La UE seguirá trabajando con los países de la región, en el marco del Convenio de Barcelona, para emprender acciones encaminadas a reducir los niveles de emisiones procedentes, en particular, del transporte marítimo, con miras a declarar el Mar Mediterráneo como zona de control de emisiones.

\footnotetext{
${ }^{115}$ Gaub, Florense: "From hot seat to power- house: managing climate change in the Southern Neighbourhood", Euromed Survey 2020 Qualitive Result, en https://www.euromesco.net/publication/euromed-Survey-results-fromhot-seat-to-powerhouse-managing-climate-change-in-the-southern-neighbourhood/
} 
Finalmente, un asunto de vital interés lo constituyen los sistemas alimentarios sostenibles, que evidencian la necesidad de administrar de manera sostenible la agricultura, la pesca y la conservación de los recursos y factores naturales de producción. Si bien es cierto que las medidas que se plantean giran en torno al intercambio de prácticas o a la promoción de la economía azul, no conviene ignorar que a la UE le interesa la integración regional en relación con la pesca y la acuicultura en el contexto de una zona de libre comercio y en el marco de la Comisión General de Pesca del Mediterráneo.

\subsubsection{La futura aplicabilidad de la propuesta}

Tras examinar el contenido de los nuevos cestos de la política euro mediterránea hemos de considerar su aplicabilidad. A la hora de poner en marcha esta nueva etapa, la UE utilizará todos sus instrumentos para garantizar una aplicación eficiente, efectiva y rápida de las acciones propuestas. Ahora bien, el diálogo político con todas las partes interesadas y a los distintos niveles, será la piedra angular de la futura cooperación. Mediante un diálogo continuo y constructivo entre la UE y sus socios se garantiza una colaboración beneficiosa, pero sobre todo una responsabilidad compartida. En el marco del diálogo se mantendrán reuniones periódicas a nivel de los ministros de Asuntos Exteriores y sectoriales, así como de altos funcionarios, mientras que igualmente se podrían convocar reuniones de Jefes de Estado y de Gobierno si fuese necesario. Asimismo, se proseguirá con los esfuerzos para reforzar la cooperación regional, subregional e interregional donde la UpM desempeñará una importante función.

Sin embargo, las pretensiones de la Unión pueden quedar en un mero borrador o proyecto si los destinatarios no asumen las aspiraciones como propias y por supuesto, si no trabajan por forjar una visión común. Por tanto, si el diálogo será la herramienta, este se vehiculará mediante el apoyo financiero que en esta ocasión se plantea a partir del compromiso de cada socio con los valores compartidos y su implicación en una aplicación real de la agenda de reformas que determine una programación conjunta. El IVDCI 2021-2027 y el Fondo Europeo de Desarrollo Sostenible Plus (FEDS+) serán los principales instrumentos tanto de financiación pública como privada en colaboración con el BEI, el BERD, los bancos de desarrollo de los Estados miembros y las instituciones internacionales.

Finalmente, conviene resaltar que la Agenda no se trata de un documento estático, sino que se caracteriza por su dinamismo y capacidad de adaptación constante por lo que se evaluarán sus progresos periódicamente. Tras la significativa declaración de los miembros del Consejo Europeo de febrero de $2021^{116}$ dando la bienvenida a la comunicación, las conclusiones del Consejo ${ }^{117}$ reiteraron su apoyo e hicieron un llamamiento a su rápida y eficaz aplicación. De modo que, aunque en los próximos meses veremos el recorrido de la Agenda, cierto sector de la doctrina y de la sociedad civil ya se ha mostrado particularmente escépticas en diversas materias que van desde los derechos humanos a la transición democrática ${ }^{118}$.

\footnotetext{
${ }^{116}$ Statement of the Members of the European Council, SN2/21, Bruselas, 26.02.2021

${ }^{117}$ Conclusiones del Consejo sobre una Asociación renovada con los países vecinos meridionales: una nueva Agenda para el Mediterráneo, 7931/21, Bruselas, 19.04.2021.

${ }_{118}$ Cfr. Mirel, Pierre: "Du Processus de Barcelone au Programme pour la Méditerranée, un partenariat fragile avec 1'Union européenne", Question d'Europe, $\mathrm{n}^{\circ} 601$ (21 junio 2021), en https://www.robert-schuman.eu/fr/questionsd-europe/0601-du-processus-de-barcelone-au-programme-pour-la-mediterranee-un-partenariat-fragile-avec-1union-e; Soler i Lecha, Eduard; Huber, Daniela: "The EU's New Agenda for its Southern neighbourhood: the case for a green and inclusive review", Policy Papers Serie, no 11 (abril 2021); Moran, James: "How new is the EU's new agenda for the Mediterranean?", CEPS, en https://www.ceps.eu/how-new-is-the-eus-new-agenda-for-themediterranean/
} 


\section{Conclusiones}

A pesar de que tradicionalmente el Mediterráneo haya sido para la UE una región periférica a la vez que una frontera, los esfuerzos y los ensayos para intensificar las relaciones entre las dos riberas mediterráneas no han dejado de plantearse desde los años setenta del pasado siglo: el diálogo euro-árabe de 1972 a 1990; el Diálogo 5+5, lanzado en 1990; el proceso de Barcelona, iniciado en 1995; la PEV en 2004 y, finalmente, la UpM, lanzada por Sarkozy en 2007 en clave de política interna francesa con el objetivo de recuperar el protagonismo en la región mediterránea, y presentada oficialmente en París en julio de 2008.

La nueva etapa, inaugurada a principios de año más bien fruto de la necesidad que de la reflexión, surge como consecuencia de la coyuntura actual que pone en riesgo la posición privilegiada de la UE en la región a causa de la creciente e imparable penetración no solo de Estados Unidos sino también de China, Rusia, Turquía e incluso de los países del Golfo Pérsico. El diseño de la propuesta carece del consenso de las partes al ser redactada en base a las necesidades e intereses europeos. Sin embargo, puede constituir un excelente catálogo de acciones necesarias para un contexto de recuperación post-pandémica y de alta conflictividad en la región, aunque es evidente que los medios, en especial los financieros, no son suficientes frente a tan ambiciosos objetivos, lo que constituye una contrariedad que ha afectado a las propuestas previas y que no presenta una solución fácil. Asimismo, podemos vaticinar que la transición esperada del partenariado al pragmatismo continuará condicionada por cuestiones de gran trascendencia e interés, como es la búsqueda constante de la legitimidad, la coherencia y la visión compartida de los problemas y sus soluciones.

Entre las distintas carencias cabe destacar, en primer lugar, la propia inercia de la UE en perseguir sus objetivos, en particular centrando el foco en la salida de la crisis derivada de la pandemia. En segundo lugar, la dificultad de promover la IED en la ribera sur mediterránea, una apuesta que nunca ha despegado del todo. En tercer lugar, el objetivo de convertir la región en una cadena de producción se aleja inevitablemente dada la intensa penetración china y el escaso interés demostrado por los propios PSM. En cuarto lugar, la transformación digital se muestra como una quimera a causa de la falta de infraestructuras y del control de las autoridades. En quinto lugar, pese a la importancia de los intercambios comerciales, este tema sigue planteándose desde una perspectiva básicamente vertical reflejando a todas luces el limitado progreso en relación con la nueva propuesta de zona de libre comercio de alcance amplio y profundo. En sexto lugar, la UE vincula el grado de asistencia financiera al compromiso con las reformas estructurales, sin embargo, no se aprecia novedad alguna en esta materia puesto que ya se ha jugado a lo largo de la AEM con todo tipo de condicionalidad: negativa, positiva y progresiva, sin obtener rendimiento y resultados apreciables. A pesar de las expectativas que despertó la primavera árabe, la mayoría de los PSM prosiguen en marcos autoritarios con un estamento militar involucrado en la gobernanza lo que entorpece las reformas. En séptimo y último lugar, la promoción de los derechos humanos y el Estado de Derecho parece un objetivo lejano y en ocasiones inalcanzable, por ejemplo, en Egipto, en Argelia o en Marruecos.

En conclusión, la UE ha intentado una vez más compatibilizar los intereses frente a los valores, sin causar entusiasmo en este propósito ni entre los Estados miembros ni en los propios PSM que lidian con sus propias y respectivas crisis. Ciertamente, la magnitud del desafío es enorme pues en caso de no generar confianza en ambas orillas puede acentuarse el declive de la efectividad de las políticas euro-mediterráneas en la región con el riesgo para la UE que ello conlleva. 


\section{Bibliografía}

Alberdi, Jokin: "Instrumentos y políticas de la cooperación europea al desarrollo para el fomento de la democracia y los derechos humanos en terceros países", en Innerarity, Daniel; Aymerich, Ignacio (coords.) (2016): Derechos humanos y Políticas públicas europeas, Paidós, Barcelona, pp. 69-88.

Albinyana, Roger: "The Union for the Mediterranean in 2017: stocking and consolidation", IEMed Mediterranean Yearbook 2017, Barcelona, IEMed, pp. 217-221.

Aliboni, Roberto: "10 ans de dialogue politique et de sécurité au sein du processus du Barcelone: une tentative d'évaluation”, Géoéconomie, no 35 (otoño 2005), pp. 101-120.

Asociación para la democracia y la prosperidad compartida con los países del Mediterráneo Meridional, COM(2011)200 final, Bruselas, 08.03.2011.

Asociación renovada con los países vecinos meridionales. Una nueva Agenda para el Mediterráneo, JOIN(2021)2 final, Bruselas, 09.02.2021.

Atalayar. Entre dos orillas, en https://atalayar.com/content/la-llegada-de-ied-marruecosaument\%C3\%B3-un-36-en-2018

Bacot-Décriaud, Michèle ; Plantin, Marie Claude : “Un joker. La charte euro-méditerranéenne pour la paix et la stabilité", en Osman, Filali ; Philip, Christian (dirs.) (2003): Le partenariat euro-méditerranéen. Le processus de Barcelone : nouvelles perspectives, Bruxelles, Bruylant, pp. 85-99.

Badia, Anna Maria: "Modelos de cooperación institucionalizada entre los Estados: puntos de conexión con la Unión por el Mediterráneo (UpM)", en Huici, Laura (coord.) (2011): La Unión por el Mediterráneo: retos de la cooperación institucionalizada en la región, Barcelona, Marcial Pons, pp. 31-52.

Balta, Paul: "El diálogo cultural en el Partenariado Euromediterráneo (PEM)”, Med 2009 Anuario del Mediterráneo, IEMed-CIDOB, Barcelona, 2009, pp. 316-322.

Barbé, Esther: "La Unión por el Mediterráneo: de la europeización de la política exterior a la descomunitarización de la política mediterránea", Revista de Derecho Comunitario Europeo, (enero/abril 2009), pp. 9-46.

Barcelona Process: Union for the Mediterranean Ministerial Conference, Marseille 3-4 November 2008, en https://ufmsecretariat.org/wp-content/uploads/2015/10/MarseilleDeclaration.pdf

Bassets, Lluís (2012): El año de la revolución: cómo los árabes están derrocando a sus tiranos, Madrid, Tecnos, 400 pp.

Bataller, Francisco; Jordán, Josep María: “Inmigración y relaciones euromediterráneas”, ICE Revista de Economía, no 846 (enero-febrero 2009), pp. 65-84.

Biad, Abdelwahad: "A strategy for conflict prevention and management in the Mediterranean", Revista CIDOB d'Afers Internacionals, nº 37 (1997), pp. 53-63.

Blanc, Antonio (2012): La Unión Europea y el Mediterráneo. De los primeros acuerdos a la primavera árabe, Madrid, Tecnos, $288 \mathrm{pp}$.

Blanc, Antonio: "El proceso euromediterráneo: una década de luces y sombras", Anuario de Derecho Internacional, vol. XXI (2005), pp. 185-225. 
Blázquez, Irene: "La dimensión mediterránea del espacio de libertad, seguridad y justicia. Del proceso de Barcelona a la Unión Europea por el Mediterráneo", Revista Electrónica de Estudios Internacionales, $\mathrm{n}^{\circ} 19$ (junio 2010), pp. 1-26.

Bremberg-Heijl, Niklas: "Between a rock and a hard place: Euro-Mediterranean security revisited", Mediterranean Politics, vol. 12, no 1 (2007), pp. 1-16.

Brimmer, Esther.: “Le voisinage de l'Union européenne: sphère de sécurité, réseau de connections ou mariage de convenance?", Politique étrangère, no 1 (2008), pp. 25-37.

Chourou, Béchir: "The (ir)relevance of security issues in Euro-Mediterranean Relations", en Tanner, Fred (ed.) (2001): The European Union as a security actor in the Mediterranean: EDSP, soft power and peacemaking in Euro-Mediterranean relations, Zürich, Forschungsstelle für sicherheitspolitik und konfliktanalyse dert ETH, pp. 57-74.

Coface for Trade, en https://www.coface.es

Cohen-Hadria, Emmanuel: "Covid-19: una prueba de resistencia para las relaciones euromediterráneas", EuroMeSCo (abril 2020), en

https://www.euromesco.net/publication/covid-19-a-stress-test-for-euro-mediterranean-

relations/

Comunicación sobre migración, COM(2011)248 final, 04.05.2011.

Comunicación sobre un diálogo para la migración, la movilidad y la seguridad con los países del Mediterráneo Meridional, COM(2011)292/3.

Conclusiones del Consejo relativas a la Estrategia Global sobre Política Exterior y de Seguridad de la Unión Europea (doc. 13202/16, de 17 de octubre de 2016), en https://data.consilium.europa.eu/doc/document/ST-13202-2016-INIT/es/pdf

Conclusiones del Consejo sobre una Asociación renovada con los países vecinos meridionales: una nueva Agenda para el Mediterráneo, 7931/21, Bruselas, 19.04.2021.

Conclusiones, EUCO 22/20, Bruselas, 10 y 11 de diciembre de 2020.

Di Stasi, Angela: "La sécurité régionale dans l'espace euroméditerranéen. Processus de Barcelone et Union pour la Méditerranée”, Revue juridique de l'Ouest, no 2 (2010), pp. 183199.

Donner une nouvelle impulsion aux actions menées par l'UE dans le domaine des droits de l'homme et de la démocratisation, en coopération avec les partenaires méditerranéens, $\operatorname{COM}(2003) 294$.

Driss, Ahmed: "El diálogo político y de seguridad euromediterráneo", Med 2009 - Anuario del Mediterráneo, IEMed-CIDOB, Barcelona, pp. 94-99.

Echeverría, Carlos: "Lecciones aprendidas por el Grupo 5+5 en sus trabajos en materia de seguridad y defensa y perspectivas de futuro", en Soler i Lecha, Eduard; Hilali, Fadela (eds.) (2009): VII Seminario Internacional sobre Seguridad y Defensa en el Mediterráneo. Conflictos regionales y estrategias de seguridad, Barcelona, CIDOB, pp. 55-61.

Echeverría, Carlos: "Valoración de los éxitos y fracasos del Proceso de Barcelona desde la perspectiva de los países del Norte de África y Oriente Medio", en Beneyto, José María (dir.) (2010): La apuesta por el Mediterráneo. Un reto para el siglo XXI, Madrid, Biblioteca Nueva, pp. 69-88.

Escribano, Gonzalo: "Reducción de espacio de las políticas euro-mediterráneas", Real Instituto Elcano, ARI 68/2017 (12 septiembre 2017), en 
http://www.realinstitutoelcano.org/wps/portal/rielcano_es/contenido?WCM_GLOBAL_CON TEXT=/elcano/elcano_es/zonas_es/ari68-2017-escribano-reduccion-espacio-politicas-euromediterraneas

Estrategia de la UE para una Unión de la Seguridad COM(2020)605 final.

European Neighbourhood Info Centre, Union for the Mediterranean: first inter-institutional meeting puts projects first, en https://web.archive.org/web/20160304082447/http://enpi-

info.eu/medportal/news/latest/31004/Union-for-the-Mediterranean:-first-inter-institutionalmeeting-puts-projects-first

European Neighbourhood Info Centre, Union for the Mediterranean: first inter-institutional meeting puts projects first, en

https://web.archive.org/web/20160304082447/http://enpi-

info.eu/medportal/news/latest/31004/Union-for-the-Mediterranean:-first-inter-institutional-

meeting-puts-projects-first

Florensa, Senen: "La Unión por el Mediterráneo: retos y ambiciones", Anuario IEMed del Mediterráneo 2010, Barcelona, IEMed, pp. 61-70.

Gaub, Florense: "From hot seat to power- house: managing climate change in the Southern Neighbourhood", Euromed Survey 2020 Qualitive Result, en https://www.euromesco.net/publication/euromed-Survey-results-from-hot-seat-topowerhouse-managing-climate-change-in-the-southern-neighbourhood/

Gaza Desalination Project - The Largest Single Facility to be built in Gaza, en https://unispal.un.org/DPA/DPR/unispal.nsf/1ce874ab1832a53e852570bb006dfaf6/11b86e44 31aa47c885257a6b0053a8cc?OpenDocument

Gillespie, Richard; Youngs, Richard (eds.) (2002): The European Union and Democracy Promotion. The Case of North Africa, Londres, Frank Cass Publishers, 219 pp.

Gillespie, Richard: “Cultura, comunidad y la Fundación Euromediterránea”, Med. 2003 Anuario del Mediterráneo, Barcelona, IEMed-CIDOB, pp. 234-236.

Grant, Charles.: “A new neighbourhood policy for the EU”, Policy Brief - Centre for European Reform, (marzo 2011), pp. 1-13.

Guinea, Mercedes: "La Política Europea de Vecindad hacia el Mediterráneo (2003-2015): impotencia de la Unión Europea ante un entorno cada vez más hostil”, Revista UNISCI/UNISCI Journal, no 39 (octubre 2015), pp. 253-272.

Hacia una Nueva Política de Vecindad, Doc. JOIN(2015)6 final, Bruselas, 04.03.2015.

Haukkala, Hiski: "The European Union as a regional normative hegemon: the case of European Neighbourhood Policy", Africa-Asia Studies, vol. 60, nº 9 (2008), pp. 1601-1622.

Hollis, Rosemary: "The UfM and the Middle East "Peace Process": an unhappy symbiosis", Mediterranean Politics, vol. 16, nº 1 (2011), pp. 99-116.

Hunt, Diana: "The UfM and development prospects in the Mediterranean: making a real difference?", Mediterranean Politics, vol. 16, nº 1 (2011), 171-192.

IED en Medio Oriente y Norte de África, Banco Mundial en https://datos.bancomundial.org/indicador/BX.KLT.DINV.CD.WD?locations=ZQ. 
Informe de la Comisión al Parlamento Europeo, al Consejo, al Comité Económico y Social Europeo y al Comité de las Regiones sobre la aplicación de los Tratados de Libre Comercio, COM(2020)705 final, Bruselas 12.11.2020.

Informe sobre la aplicación de la Revisión de la Política Europea de Vecindad, Doc. JOIN(2017)18 final, Bruselas, 18.05.2017.

Johansson-Nogués, Elisabeth: "The UfM's institutional structure: making inroads towards "coownership?", Mediterranean Politics, vol. 16, nº 1 (2011) pp. 21-38.

Khader, Bichara "El círculo de amigos (ring of friends): la nueva Política Europea de Vecindad (PEV)", en Blanc Altemir, Antonio (ed.) (2008): Europa Oriental: en la encrucijada entre la Unión Europea y la Federación Rusa, Lleida, Centre de Cooperació Internacional de la Universitat de Lleida-Programa Jean Monnet (Comisión Europea), pp. 137-170.

Le Morzellec, Joëlle: "Le partenariat euro-méditerranéen: la consolidation d'une zone de paix et de stabilité", en Osman, Filali; Philip, Christian (dirs.) (2003): Le partenariat euroméditerranéen. Le processus de Barcelone: nouvelles perspectives, Bruxelles, Bruylant, pp. 6583.

Mahjoub, Azzam: "La Zona de Libre Comercio entre la Unión Europea y los Países Socios Árabes del Sur y Este del Mediterráneo: breve resumen de la situación y perspectivas", Med 2009 - Anuario del Mediterráneo, IEMed-CIDOB, Barcelona (2009), pp. 256-259.

Marquina, Antonio: "El Diálogo Mediterráneo de la OTAN, 2. Nuevas ilusiones y un espejismo: la democratización y la transformación del espacio mediterráneo", Comentario UNISCI, n. ${ }^{\circ} 134$ (2018), 4 pp.

Marquina, Antonio: "La cooperación social, cultural y humana en el Mediterráneo", en Beneyto, José María (ed.) (2010): La apuesta por el Mediterráneo. Un reto para el siglo XXI, Madrid, Instituto Universitario de Estudios Europeos-Universidad CEU San Pablo, pp. 121142.

Marquina, Antonio: "La asociación de seguridad de la Conferencia Euro-Mediterránea diez años después: la anábasis", UNISCI Discussion Papers, nº 9 (2005), pp. 73 y ss.

Marquina, Antonio: "Seguridad y estabilidad política en el Mediterráneo", Revista CIDOB d'Afers Internacionals, $\mathrm{n}^{\circ} 37$ (1997), pp. 39-52.

Mirel, Pierre: "Du Processus de Barcelone au Programme pour la Méditerranée, un partenariat fragile avec l'Union européenne", Question d'Europe, $\mathrm{n}^{\circ} 601$ (21 juin 2021), en https://www.robert-schuman.eu/fr/questions-d-europe/0601-du-processus-de-barcelone-auprogramme-pour-la-mediterranee-un-partenariat-fragile-avec-l-union-e

Moran, James: "How new is the EU's new agenda for the Mediterranean?", CEPS, en https://www.ceps.eu/how-new-is-the-eus-new-agenda-for-the-mediterranean/

Moratinos, Miguel Ángel: "El Mediterráneo, 25 años después”, El País, 20 de noviembre de 2020, en https://elpais.com/opinion/2020-11-19/el-mediterraneo-25-anos-despues.html

Nicolaïdis, Dimitri: "Creación de la Fundación Euromediterránea para el Diálogo entre las Culturas y las Civilizaciones”, Med. 2003 - Anuario del Mediterráneo, Barcelona, IEMedCIDOB, pp. 92-93.

Nieto Fernández, María Isabel (coord.) (2020): La UE y el Mediterráneo a la luz de la Estrategia Global de Seguridad de la Unión. Retos futuros en las políticas de vecindad, seguridad y defensa, Madrid, Dykinson, pp. 63-106. 
Pierini, Maurizio: "The crisis of the European project and its consequences for the EuroMediterranean agenda", IEMed Mediterranean Yearbook 2018, Barcelona, IEMed, pp. 114118.

Plan de Acción de la UE para los Derechos Humanos y la Democracia 2020-2024 JOIN(2020)5.

Política Europea de Vecindad, en https://ec.europa.eu/neighbourhood-enlargement/europeanneighbourhood-policy_en

Propuesta de Reglamento del Parlamento Europeo y del Consejo por el que se establece el Instrumento de Vecindad, Desarrollo y Cooperación Internacional, COM(2018)460 final, Bruselas, 14.06.2018.

Reglamento (UE) n ${ }^{\circ}$ 235/2014 del Parlamento Europeo y del Consejo, de 11 de marzo de 2014, por el que se establece un instrumento financiero para la democracia y los derechos humanos a escala mundial (2014-2020).

Reiterer, Michael: "From the French Mediterranean Union to the (European) Barcelona Process: The Union for the Mediterranean as a part of the European Neighbourhood Policy", European Foreign Affairs Review, vol. 14, nº 3 (2009), pp. 313-336.

Resolución legislativa del Parlamento Europeo de 27 de marzo de 2019, sobre la propuesta de Reglamento del PE y del Consejo por el que se establece el Instrumento de Vecindad, Desarrollo y Cooperación Internacional, en https://www.europarl.europa.eu/doceo/document/TA-8-2019-0298_ES.html\#title2

Schmid, Dorothée: "Le partenariat, ¿une méthode européenne de démocratisation en Méditerranée?", Politique étrangère, no 3 (2005), pp. 545-557.

Sidlo, Katarzyna: "Digital transformation in the Southern Neighbourhood" Euromed Survey 2020 Qualitive Result, en

https://www.euromesco.net/wp-content/uploads/2021/06/ES11_Qualitative-3-Sidlo-102110.pdf

Soler i Lecha, Eduard; Huber, Daniela: "The EU's New Agenda for its Southern neighbourhood: the case for a green and inclusive review", Policy Papers Serie, $\mathrm{n}^{\circ} 11$ (abril 2021), 10 pp.

Soler i Lecha, Eduard: "El Mediterráneo, veinticinco años después", Anuario Internacional CIDOB, Barcelona Centre for International Affairs (junio 2020), pp. 176-184.

Solera, Gianluca: "La cooperación cultural en el espacio mediterráneo: apuntes para un decálogo", en Beneyto, José María (ed.) (2010): La apuesta por el Mediterráneo. Un reto para el siglo XXI, Madrid, Instituto Universitario de Estudios Europeos - Universidad CEU San Pablo, pp. 143-159.

Statement of the Members of the European Council, SN2/21, Brussels, 26.02.2021

World Development Indicators, The World Bank, en https://datatopics.worldbank.org/worlddevelopment-indicators/

Tocci, Nathalie; Cassarino, Jean-Pierre: "Rethinking the EU's Mediterranean Policies Post 1/11", Istituto Affari Internazionali (IAI) Working Papers, vol. 11, nº 6 (marzo 2011), 29pp.

Tovias, Alfred: "La condicionalidad y la política europea de Vecindad", Cuadernos Económicos: ICE , nº 846 (enero-febrero 2009), pp. 7-17.

UfM roadmap for action. The Union for the Mediterranean. An action-driven organization with a common ambition adopted by the UfM Ministers of Foreign Affairs, on 23 January 2017 in 
Barcelona, en https://ufmsecretariat.org/wp-content/uploads/2017/10/UfM-Roadmap-foraction-2017.pdf

Un presupuesto para Europa 2020. Parte II: Fichas sobre Políticas, COM(2011)500 final Parte II, Bruselas, 29.06.2011, p. 50.

Una nueva respuesta a una vecindad cambiante, $\operatorname{COM(2011)303~final,~Bruselas,~25.5.2011.~}$

Union for the Mediterranean - Activity Report 2015, en https://ufmsecretariat.org/wpcontent/uploads/2016/06/UfM-Activity-Report_FINAL_WEB.pdf

Union for the Mediterranean - Activity Report 2016, en https://ufmsecretariat.org/wpcontent/uploads/2017/05/2016-Annual-Report_-UfM.pdf

Yáñiz, Federico: "El Diálogo Mediterráneo de la OTAN y las crisis árabes”, Real Instituto Elcano - ARI, $n^{\circ}$ 108/2011 (junio 2011), en

http://www.realinstitutoelcano.org/wps/portal/rielcano_es/contenido?WCM_GLOBAL_CON TEXT=/elcano/elcano_es/zonas_es/defensa+y+seguridad/ari108-2011 